\title{
A Developmental Approach to Drug-induced Liver Injury in Newborns and Children
}

\author{
G. Faa ${ }^{*, 1}$, J. Ekstrom ${ }^{2}$, M. Castagnola ${ }^{3}$, Y. Gibo ${ }^{4}$, G. Ottonello ${ }^{5}$ and V. Fanos ${ }^{5}$ \\ ${ }^{1}$ Department of Pathology and ${ }^{2}$ Division of Pharmacology, Institute of Neurosciences and Physiology, University of Gothenburg, \\ Goteborg, Sweden; ${ }^{3}$ Institute of Biochemistry, Catholic University of Rome, Rome, Italy; ${ }^{4}$ Department of Gastroenterology, \\ University of Matsumoto, Matsumoto, Japan; ${ }^{5}$ Department of Neonatology, University of Cagliari, Cagliari, Italy
}

\begin{abstract}
The liver represents the major site of drug metabolism in humans. The developmental changes that occur in the liver's metabolic activity during fetal life and in the perinatal period are at the basis of the varied sensitivity of human newborns to many drugs. The decreased capacity of the fetal and newborn liver to metabolize, detoxify, and excrete drugs - total cytochrome P450 content in the fetal liver being $30 \%$ to $60 \%$ of adult values - may explain the prolonged actions of many drugs in the newborn, as well as less their potential toxicity. On the other hand, the low levels of phase I (activation) enzymes, producing more polar reactive and often toxic metabolites, could explain the lower incidence of adverse effects of some drugs reported in newborns. Moreover, the greater capacity of newborns to synthesize glutathione is at the basis of their ability in inactivating many toxic metabolites. Here we review the acute and chronic liver toxicity due to the most widely used drugs in the neonate. We will discuss in detail the biochemical profile of the fetal and neonatal liver, and the toxic metabolites formed during the metabolism of the most widely used drugs in the neonate. The histological picture of liver disease related to the therapeutic use of drugs will be discussed, with particular emphasis on the mode of cell death involved in hepatitis induced by different drugs most frequently utilized in the neonatal intensive care units.
\end{abstract}

Keywords: Drugs, hepatotoxicity, human newborn, DILI, cytochrome P-450.

\section{INTRODUCTION}

The liver plays a central role in the metabolism of xenobiotics, including drugs, being mainly responsible for their metabolism and excretion. The metabolism of the vast majority of drugs gives rise, inside the hepatocytes, to the generation of toxic metabolites, predisponing the liver to drug toxicity [1]. Hundreds of drugs have been implicated in the aetiology of hepatotoxicity and associated with adverse events characterized by a primary liver involvement [2]. The clinical picture of hepatitis associated to drugs, recently named drug-induced liver injury (DILI) [3] or drug-induced liver disease (DILD) [4], ranges in severity from a mild and reversible increase in serum levels of transaminases up to the insurgence of acute fulminant hepatic failure [5].

As for drug metabolism, the human neonate should be considered a very special patient population, a unique drug recipient [6], given the state of immaturity at birth and the daily evolution of many metabolic functions, including drug carriers at the intestinal level, intracellular transporters in the enterocytes, carriers in blood, drug metabolizing enzymes in liver cells, and renal function, all factors which have a great influence on the efficacy and toxicity of medications [7]. As a consequence of the incomplete maturity of so many functions at birth, bioavailability of drugs in newborns and, in particular, in preterms, shows marked differences as compared with that observed in adults, regarding absorption, distribution, metabolism and excretion [8]. Developmental aspects should be considered even regarding drug conjugation with special reference to glucuronidation, due to the significant decreased ability of neonates to metabolize the vast majority of drugs $[9,10]$.

Pharmacokinetic differences between neonates, children and adults may play a relevant role in the age-related differences of adverse effects to drugs between these different populations. For some drugs there is an increased risk of adverse effects in neonates, for others a protection against hepatotoxicity seems to be present $[11,12]$. Recent studies aimed at evaluating pediatric drug dosing guidelines for intensive care newborns, underline the scarcity of drug studies in this population, and lay stress on the widely different dosing guidelines in the four most commonly used drug

*Address correspondence to this author at the Full Professor of Pathology, Istituto di Anatomia Patologica, Ospedale San Giovanni di Dio, Via Ospedale n. 60, 09124 C A G L I A R I, Sardinia, Italy; Tel: 0039.070.6092369 - 2487; Cell: 0039.3687850790; Telefax: 0039.070.657882; E-mail: gavinofaa@gmail.com formularies in the intensive care units, regarding doses per kilogram, dose description and dosing regimen [13].

Recently, other factors that may have a potential influence on pharmacokinetic of drugs have been proposed. Among them, biological rhythms, including the sleep-wake, the circadian temperature rhythms, and the circadian secretion of many hormones have been suggested to deeply influence the action and toxicity of drugs $[14,15]$. Perinatal asphyxia influences drug toxicity and seems to increase aminoglycoside ototoxicity [16]. Therapeutic whole body hypothermia for the treatment of hypoxic-ischemic encephalopathy in neonates has been shown to influence the metabolism of many drugs. Phenobarbital administered under hypothermia resulted in higher plasma concentrations and longer half-life than in normothermic newborns, suggesting a lower rate of liver metabolism by the hypothermic liver [17]. Moreover, delayed time of maximal serum concentration, considerably higher serum values and lower total body clearance, were reported for topiramate in neonates under whole body hypothermia, suggesting lower absorption and elimination when compared to normothermic newborns [18]. Size and gestational age at birth should also be taken into account when drug dosing and toxicity are considered: the pharmacokinetic parameters in the premature neonates have been shown to differ so significantly from those of full term newborns [19], leading to the recent development of a new research field defined developmental pharmacology, whose goal is the study of the impact of birth and of gestational age on drug response in the perinatal period [20]. Developing pharmacology should also induce neonatologists working in Neonatal Intensive Care Units (NICUs) to continuously adapt drug dosage for a single newborn, given the daily maturation of his/her drug metabolizing system, with relevant consequences in the pharmacokinetics of many drugs.

The purpose of this article is to provide a brief review of the pharmacokinetic differences between neonates and adults, to show the peculiarities of liver function at birth, particularly in preterm infants, the toxic mechanisms of liver injury in the perinatal period, and the histological and clinical markers of liver disease due to the most frequently utilized drugs in NICUs.

\section{PECULIARITIES OF PHARMACOKINETICS IN THE PERINATAL PERIOD}

\section{Absorption and Bioavailability of Drugs}

Clinical pharmacokinetics in the newborn, and in particular oral absorption of many drugs, may be modified by the different gastric 
and intestinal $\mathrm{pH}$, by differences in the gastrointestinal emptying time, by the peculiar composition of the gastrointestinal flora at birth, and by the decreased enzyme activity in the immature intestinal epithelium in the perinatal period $[21,22]$. The gastric $\mathrm{pH}$ ranges from 2.3 to 3.6 in full term newborns, from 6 to 8 in preterm infants, and reaches the typical adult values (1.4 to 2.0$)$ by the age of 1 to 2 years. As a consequence, the gastric absorption of many drugs including phenobarbital, that depends on the gastric $\mathrm{pH}$, is always decreased at birth, and may show significant differences between preterm and full term newborns. The lower the $\mathrm{pH}$ relative to the $\mathrm{pK}_{\mathrm{a}}$, the greater fraction of protonated drug is found. As a result, a weak acid at acid $\mathrm{pH}$ will be more lipid-soluble because it is uncharged and uncharged molecules move more readily through a lipid (nonpolar) environment, like the enterocyte membrane, than charged molecules. Similarly, a weak base at alkaline $\mathrm{pH}$ will be more lipid-soluble because at alkaline $\mathrm{pH}$ a proton will dissociate from molecules leaving them uncharged and again free to move through lipid membrane structures. Since lipid diffusion depends on adequate lipid solubility, drug ionization reduces a drug's ability to cross a lipid bilayer. Drugs are, in general, weak acids or bases. A weak acid is a neutral molecule that dissociates into an anion (negatively charged) and a proton (a hydrogen ion). For example, neutral aspirin acetylsalicylic acid $\left(\mathrm{C}_{8} \mathrm{H}_{7} \mathrm{O}_{2} \mathrm{COOH}\right)$, is in equilibrium with its anion $\left(\mathrm{C}_{8} \mathrm{H}_{7} \mathrm{O}_{2} \mathrm{COO}-\right)$ and a proton $\left(\mathrm{H}^{+}\right)$. In particular, developmental changes have been reported for phenobarbital absorption rate in the gastrointestinal tract in neonates, with low absorption levels at birth and marked increase, up to ten times, in the perinatal period. On the contrary, percutaneous absorption is very high at birth, and decreases only slowly at the adult levels, that are reached by 3 to 5 years of life. Therefore, skin application of drugs, in particular of steroids, to newborns requires special attention [23]. An example of peculiarities in neonatal pharmacokinetics and pharmacodynamics is presented in (Table 1).

\section{Blood Transport}

Drug distribution is affected by the low serum protein levels typical of neonates, which show a decreased binding capacity to the vast majority of drugs, significantly altering the ratio of unbound to total plasma concentration of multiple drugs. The serum protein binding rate for acidic drugs has been shown to reach adult values by around 1 year of life, whereas for basic drugs the adult levels are reached by 3 to 4 years [23]. As a consequence, in the neonate, unbound plasma concentrations are needed for therapeutic drug monitoring, to prevent dose-dependent adverse effects. A recent study carried out on epileptic neonates and infants, clearly showed that the serum concentrations of unbound valproic acid (VPA) in newborns noticeably differed from the reference adult values, suggesting that the unbound concentration of VPA, as well as that of other drugs, should be explicitly determined via therapeutic drug monitoring activities, due to the poor applicability of estimation methods for adults [24].

\section{Distribution}

The distribution volumes of newborns show marked peculiarities as compared to distribution volumes in adults, which are normally reached around 3 to 5 years of life. As for the body fat, it has been calculated to be $12 \%$ in full term newborns, ranging from 3 up to $12 \%$ in preterms, as compared to $18 \%$ in adults. The extracellular water volume is $60 \%$, compared to $20 \%$ in adults, whereas the total body water has been estimated around $75 \%$ for neonates and $50 \%$ for adults. As a consequence of these marked differences, the distribution volume in the perinatal period is significantly larger for hydrophilic drugs, and smaller for lipophilic drugs than in adults [23]. In clinical practice, hydrophilic drugs with a high volume of distribution in adults should be normalized to body weight in neonates, whereas hydrophilic drugs with a low volume of distribution in adults should be normalized to body surface area [25].

\section{Hepatic Metabolism of Drugs in the Neonate}

The human liver plays a central role in the uptake, transport, metabolism and excretion of the vast majority of xenobiotics, including drugs [26]. The hepatocytes, highly polarized cells with distinct sinusoidal and biliary poles, have an essential function in selectively removing lipid-soluble drugs weighing more than 500 daltons from the sinusoidal lumen and, utilizing specific active transporters located on the cell membrane, allow their passage across the hepatocytic membrane into their cytoplasm [27]. The second step of the interaction between drugs and liver cells is represented by binding of internalized drugs to cytosolic proteins and chaperons, that operate the intracellular drug transport towards the enzymes of the drug metabolizing system [28]. These can be subdivided into two main groups: phase 1 enzymes are involved in reactions of oxidation, hydroxylation, and other reactions mainly mediated by cytochrome P-450 (CYP); phase 2 enzymes are mainly involved in esterification reactions, that originate conjugates with sulfate, glucuronic acid, amino acids and glutathione molecules, generally resulting in increased water solubility, decreased pharmacologic activity and eventually detoxification of xenobiotic compounds [29]. The final step of the hepatic drug metabolism is characterized by the excretion of drugs, their metabolites and their conjugates into bile or into the sinusoidal circulation. These pathways, recently referred to as phase 3 of the hepatic drug metabolism, include the multidrug resistance (MDR) protein and the multidrug resistance-related proteins [30].

However, under conditions of increased levels of the drug, when phase 1 and phase 2 enzymes activity is not well balanced, in the presence of genetic alterations determining changes in the expression of hepatobiliary drug-transporters or of drugmetabolizing enzymes, the same mechanisms may cause the production of toxic metabolites, leading to DILI [31].

Pharmacokinetic and pharmacodynamic differences have been reported in recent years, between children, particularly newborns and preterm infants, and adults [8] as for drug metabolism. The

Table 1. Anatomo-Functional Immaturity and Management of Antibiotics in the Newborn

\begin{tabular}{|c|c|c|c|c|}
\hline & Modified Parameter & Pharmacokinetics & Example & Practical Consequence \\
\hline \hline High Extracellular Fluids & $\uparrow$ Distribution Volume & $\downarrow$ Peak & Gentamicin & \multirow{1}{*}{ Dosage per dose (Kg/dose) } \\
\hline Low Serum Proteins & $\downarrow$ Drug-Proteins binding & $\uparrow$ Free Fraction & Ampicillin & Dose Reduction \\
\hline Immaturity of Liver Enzyme & $\downarrow$ Metabolism & $\downarrow$ Clearance & \multirow{2}{*}{ Cloramphenicol } & Dose Reduction \\
\hline Renal Immaturity (Glomerular and Tubular) & $\downarrow$ Excretion & $\uparrow \mathrm{t} 1 / 2$ & \multirow{2}{*}{ Gentamicin } & \multirow{2}{*}{ Reduction of Frequence of Administration } \\
\hline
\end{tabular}


metabolic profile of the neonate has been shown by several studies to significantly differ in the absorption, distribution, metabolism and excretion of many drugs, due to marked biochemical differences in sulphation, glucuronidation, conjugation and elimination [7, 10, 32-34]. It has been shown that certain biotransformation pathways, including hydroxylation and glucuronidation, demonstrate only limited activity at birth [35], whereas other pathways, such as sulphate or glycine conjugation, appear very efficient, more than in adult subjects, in the newborn [33]. In clinical practice, this physiological diversity has important consequences on drug dosing for different drugs. Children need weight-corrected doses, higher than adult doses, for drugs that are metabolically eliminated solely by specific CYP isoenzymes, including CYP1A2, CYP2C9 and CYP3A4. In contrast, weightcorrected doses for drugs eliminated by renal excretion or metabolism involving $\mathrm{N}$-acetyltransferase 2, or uridine diphosphate glucuronosyltransferase (UDGT) are similar in newborns and adults [36].

In addition, newborns present a greater capacity, when compared to adults, to sinthesize glutathione, thereby more effectively inactivating toxic metabolites produced by the activity of phase 1 enzymes on many drugs [35]. Some enzyme activity, including thymidine kinase and ornithine decarboxylase, is high during foetal life and at birth, and falls during the postnatal period. On the contrary, other liver enzymes, including aspartate aminotransferase, show a low expression in the human foetus, but increase their expression after birth [37]. Another group of liver enzymes is expressed only in the perinatal period, and increases after birth.

These developmental marked modifications of the machinery utilized by hepatocytes in the metabolism of drugs place the newborn, the preterm infant and the developing foetus at a different risk from drug-toxicity as compared to adults, and are responsible for the different effects of the same drug on liver at various stages of development. For example, the lower expression in the newborn of the liver enzymes involved in glucuronide conjugation, has been proposed to be possibly responsible for the gray infant syndrome from chloramphenicol [35].

The balance between activation (phase 1 enzymes) and detoxification reactions (phase 2 enzymes) is crucial in the elimination of drug metabolites [38]. Many factors may influence this critical balance, including some enzymatic inducers, that may affect disproportionately phase 1 or phase 2 enzymes.

Taken all together, it becomes apparent that children cannot be regarded as "small adults" with respect to drug therapy: they often need a different fraction of drug per $\mathrm{Kg}$ of body weight as compared to adults. For example as for digoxin, a drug excreted by glomerular filtration but also secreted by the tubular renal cell, newborns need threefold higher doses per $\mathrm{Kg}$ body weight than adults [39].

The frequent observation in clinical practice of marked interindividual differences in drug responses among neonates, and particularly among preterms, has given birth to the concept of "tailor made" drug therapy in neonatology, i.e. a customized drug therapy based on the peculiar metabolic system of each neonate, irrespectively of the "general", often adult-related therapeutic protocols [7].

\section{Renal Excretion and Metabolism}

A thorough examination of the expression pattern of the main drug transporters in the newborn kidney, as well as in all stages of human development, has yet to be carried out. As a consequence, data on the functional maturation of the drug transporters' system in preterms, in low birth weight newborns, and in neonates mainly depend, in clinical practice, on the ability of the neonatologist to investigate and understand the degree of functional maturation of each neonate, by performing "in vivo" specific pharmacokinetic analyses in order to establish the correct drug dosage in every single newborn. Given the slower rate of biotransformation activity typical of the newborn liver, which includes slower rate of biotransformation and slower overall elimination of drugs, in the neonate drug elimination relies heavily on renal excretion [7].

\section{DRUG INDUCED LIVER INJURY (DILI)}

\section{Pathogenesis of Drug-Related Liver Injury in Newborns}

The biotransformation of xenobiotics, including drugs, in the human liver at birth presents many peculiar features as compared to adults, which result in a different balance between the two most important phases of the hepatic drug metabolism: bioactivation, mainly due to the action of phase 1 enzymes, and detoxification, of which phase 2 enzymes are responsible. As previously stated, the balance between these factors is not stable in the newborn mentioned, but it changes day by day according to the rapid development of phase 1 and phase 2 enzymes in the postnatal period [40]. Temporal dynamics, individual polymorphisms, and balance between phase 1 and phase 2 enzymes have been indicated as the main factors having a profound impact on drug biotransformation and susceptibility to adverse toxic effects [28].

The CYP (cytochrome P-450) gene superfamily found in both eukaryotes and prokaryotes has grown from a putative ancestral gene formed more than 3.5 billion years ago [41]. So far, 79 gene families have been described: of these, 14 are found in mammals, families 1-4 being the most important ones in the metabolism of xenobiotics in man [42]. The ontogeny of the most important CYPs taking part in drug metabolism in human liver is characterized, at birth, in general by their markedly decreased activity, total CYPs content in fetal liver being estimated between $30 \%$ and $60 \%$ of adult values $[43,44]$. But differences between neonates and adults are not simply quantitative. It has been shown that certain biotransformation pathways, including hydroxylation and glucuronidation, demonstrate very limited activity at birth, whereas other pathways, such as sulphate or glycine conjugation, appear very efficient in the newborn [33]. Biotransformation of most of the commonly used drugs is catalyzed by CYPs and uridine diphosphate glucuronosyltransferase (UGT) enzymes [8]. The human hepatic CYP is approximately composed of 50 isoenzymes, grouped into three main families, CYP1, CYP2, CYP3 [44]. Eight isoenzymes are mainly involved in the metabolism (oxidation) of most drugs (CYP1A2, CYP2A6, CYP2C8, CYP2C9, CYP2C19, CYP2D26, CYP2E1, and CYP3A4). The most abundant isoenzyme in the human liver is CYP3A4, which accounts for about $30 \%$ of the total liver CYP, and is generally thought to be involved in the oxidation process of more than $50 \%$ of drugs [45]. CYP2D6 accounts for $2 \%$ or less of the hepatic CYP, but it is responsible for the oxidative metabolism of approximately $12 \%$ of clinically relevant drugs [46]. Moreover, CYP2D6 activity was detectable in neonates only by 2 weeks of postnatal age, with values at birth no greater than 3 to $5 \%$ the levels observed in the adult liver [47]. Some members of CYP families are detected early in organogenesis, whereas others are not detectable at birth and develop at different rates in the postnatal period. Some examples of temporal switching in the perinatal period: CYP3A7 is highly expressed in the foetal liver, and disappears after birth; CYP3A4, undetectable during gestation, dramatically increases at 1 postnatal week, and reaches adult levels around 1 month after birth. The knowledge of these differences in the different activity of the different CYP family members in neonates, may explain the increased risk of adverse effects of some drugs in the newborn. The low content of CYP3A4 in the neonate has been reported to be mainly responsible for the impaired metabolism of cisapride in the perinatal period, resulting in accumulation of the drug and cardiac 
toxicity [48]. The classes of drug substrates of CYP3A4 enzyme include antibiotics, antivirals, antifungals, immunomodulators, benzodiazepines, proton pump inhibitors, steroids and acetaminophen [28]. As a consequence, neonates, in spite of the high ratio of liver size to body size, often show a decreased ability to metabolize the vast majority of drugs routinely utilized in a NICU, drugs which are eliminated through CYP-dependent metabolism. The low levels of CYP enzymes, and in particular of CYP3A4 isoform, in the newborn make the neonate particularly susceptible to overdosage-related toxicity from many drugs, due to the blocking of drug excretion, which necessitates the action of phase 1 enzymes, aimed at rendering more hydrophylic (and excreatable) the lipophylic drugs. As a consequence, the neonate shows a prolonged half-life for most drugs [37].

The vulnerability of the human liver to drug toxicity in the perinatal period is not restricted to phase 1 enzymes deficiency, glucuronide conjugation capacity being markedly reduced at birth [35]. Glucuronidation represents one of the main detoxification pathways in humans, and undergoes relevant developmental changes during the perinatal period. In children younger than 2 years, and in particular in neonates and in preterm infants, the hepatic glucuronidation activity has been demonstrated to be markedly reduced [49]. Different classes of drugs, including ibuprofen and steroid hormones, are normal targets for the detoxification action of UGT. The low UGT activity in the neonatal liver might be responsible for the accumulation of reactive metabolites originating from different drugs by the action of phase 1 enzymes, which, in the absence of adequate glucuronidation activity, could not be excreted and could accumulate inside liver cells, causing lipid peroxidation, interfering with protein synthesis, damaging plasma membranes and inducing cell death Fig. (1).

\section{DRUG METABOLIZING SYSTEM}

Phase 1 Enzymes P450

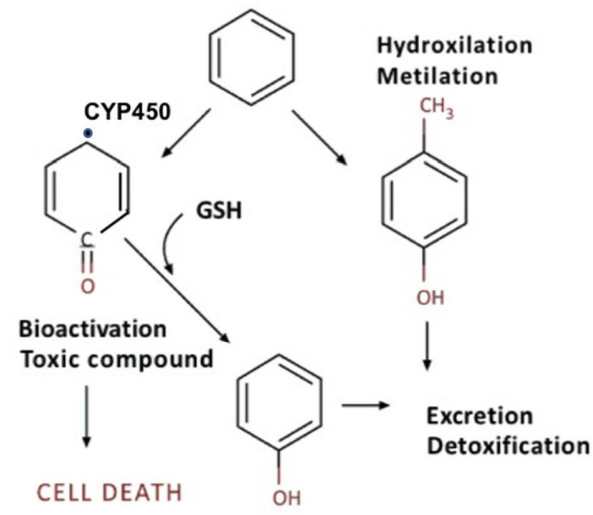

Fig. (1). Activity of phase I enzymes of the drug metabolizing system may allow drug elimination by increasing water solubility of the drug, but may also bioactivate the drug, giving rise to toxic metabolites.

Bile formation is essential for the excretion of many xenobiotics, including the glucuronide and the glutathione conjugates of many drugs [50]. This essential function predisposes the human liver to cholestatic hepatocellular injury, which accounts for almost half of all hepatic drug toxicity including the neonatal period $[29,51]$. The target of injury caused by the toxic action of drugs, or their active metabolites, can vary, from the hepatocyte, to the bile canaliculus, resulting in intrahepatic cholestasis, or to a obstructive cholangiopathy where the initial site of injury is located at various levels of the biliary tree $[52,53]$. The ability to synthesize and excrete bile components, including bilibirubin and bile acids, is immature in the neonate, and, when associated with low glucuronidation activity, may favour the insurgence of physiologic jaundice. Taken all together, these developmental changes place the developing fetus and the preterm infant at differential risk for cholestasis from toxic injury caused by different drugs [37].

Another factor to be taken into consideration when approaching to drug metabolism and toxicity in the neonate, is represented by genetic polymorphisms, which may profoundly influence expression and function of drug-metabolizing enzymes in different subjects, resulting in marked interindividual differences in metabolism and in the ability of excretion of specific drugs [28]. Interindividual differences in drug responses in clinical practice in NICU centers can be attributed to polymorphisms in genes encoding drug-metabolizing enzymes [54] and drug transporters [55], resulting in a high variability of the individual response to a drug in terms of efficacy and toxicity. All CYP enzymes, with one exception, are polymorphic, particular alleles causing qualitative and/or quantitative interindividual differences in the enzymatic activity and in the metabolism of specific drugs. Genetic polymorphisms of CYP enzymes have been proposed as one of the factors that contribute to the pharmacokinetic variability of drugs, allowing to identify extensive metabolizers and poor metabolizers, with major clinical implications for drug dosing and drug response [56]. Among the different CYP isoforms, CYP2D6 is highly polymorphic, with more than 80 known alleles, several of which have significant functional impact. 14 CYP2D6 alleles, that account for more than $90 \%$ of the variability observed, have been identified in different populations [57]. Polymorphisms have also been reported for phase 2 enzymes. UGT isoforms have been implicated as principally responsible for the interindividual variability in acetaminophen glucuronidation and for the marked interindividual variability in susceptibility to acetaminophen toxicity observed in clinical practice [58].

\section{Clinical Presentation and Pathological Findings of DILI in Neonates}

DILI is an important cause of potentially severe acute and chronic liver injury, occurring at any age and following the administration of more than 300 drugs [59], 30\% being associated with disproportionally higher reporting frequency of liver injury [2]. The clinical picture of DILI in neonates is mainly characterized by a subclinical onset, with mild modifications of biochemical tests of liver function, in the absence of any pathognomonic clinical symptom. The diagnosis of DILI in neonates is, in the vast majority of cases, one of exclusion, and is confirmed after clinical improvement following discontinuation of the causative drug. Complete recovery occurs in the majority of patients, but acute liver failure and death have been rarely reported. Clinically and histologically, DILI can mimick any known liver disease of other origin, in the absence of any pathognomonic feature [60]. Diagnosis of DILI is therefore challenging, with considerable interobserver variability in assessing causality [61]. Risk factor ascertainment and early detection strategies have been proposed during the years [62, 63], and significant initiatives such as the Drug-Induced Liver Injury Network (DILIN) have been established with the aim of advancing understanding of DILI and favoring a prompt diagnosis of the disease [64]. A statistically significant relationship has been observed between the daily dose of oral medicines and reports of liver failure due to DILI [65]. The development of acute hepatitis in patients with a diagnosis of DILI may be severe, being associated with a 9 to $12 \%$ mortality rate: patients with severe coagulopathy or encephalopathy are referred for potential liver transplantation [66].

Hepatotoxic agents may be classified as intrinsic and idiosyncratic, also defined as facultative [67]. Hepatotoxicity due to intrinsic drugs occurs in every subject exposed to a proper toxic 
dosage, is dose-dependent and may be reproduced in experimental animals. Acetaminophen is the typical intrinsic hepatotoxin. Idiosyncratic adverse reactions to drugs, the vast majority in clinical practice, are unpredictable, and occur in subjects who, for different reasons, do not tolerate that specific drug. These reactions are often explained by the inability of the subject to correctly metabolize the compound, due to a congenital reduced activity or to the absence of a peculiar enzyme, resulting in the accumulation of the drug and/or of its toxic metabolites.

In clinical practice, adverse liver reactions to drugs are mainly classified as acute and chronic [68]. Acute hepatic injury is characterized by a cytotoxic injury with prominent elevation of transaminases, or by cholestatic injury, resembling obstructive jaundice. Chronic drug-related liver disease may be indistinguishable, even at histology, from a viral chronic hepatitis. The association, in the liver biopsy, of lymphocytic infiltrate with unexplained steatosis and/or bilirubinostasis, in the absence of viral markers, might induce clinicians to investigate the possibility of toxicity due to drugs, discontinuation of which is frequently followed by resolution of liver disease.

\section{Histological Changes in DILI}

Liver disease caused by adverse reactions to drugs may be classified according to the elementary lesions observed, at histological level, in liver biopsies from the affected patients. Drugs may cause derangement of one or more of the multiple functions of the hepatocytes: bile formation and excretion, synthesis of proteins, trace metals metabolism, regulation of blood glucose and lipid metabolism.

Cholestasis is one of the typical consequences of drug hepatotoxicity [26]. The morphological cholestatic lesions are bilirubinostasis, defined as the accumulation in the hepatocytes and/or in bile canaliculi of bile plugs, and cholatestasis, i.e. the accumulation of bile salts resulting in a process of feathery degeneration of hepatocytes and leading to bile acid-mediated apoptosis. Bilirubinostasis and cholatestasis are the principal morphological signs indicating the interference of a drug on bile formation and excretion. The reduced capacity to synthesize and excrete bile, typical of every newborn, makes the neonate particularly susceptible to cholestasis from toxic injury due to drugs [69].

A very frequent elementary lesion observed in liver cells, due to adverse drug reaction, is cell death, including apoptosis and necrosis [5]. Apoptotic cell death is characterized by the appearance of apoptotic globules, eosinophilic roundish globules that undergo phagocytosis by Kupffer cells [70]. Liver cell necrosis is characterized by ballooning of hepatocytes, followed by rupture of the cell membrane and lysis, with immission of hepatocytic enzymes, including transaminases, into the sinusoidal lumen. Oxidative stress is one of the main mechanisms that mediate druginduced liver cell death. Many chemicals, including many drugs, have been shown to increase the production of free radical species, leading to hepatocyte cell death [71]. Cell necrosis, in the majority of drug-related liver disease, is characterized by a zonal distribution, involving the perivenular (zone 3), the periportal (zone 1) or the mid-zone, depending on the drug involved. Perivenular necrosis is the most common type, and can be the result of hepatotoxicity due to many toxins, including aflatoxins, ketoconazole, para-aminosalicylic acid, valproic acid, rifampicin, indomethacin, and paracetamol [72]. Periportal (zone 1) necrosis is caused by a few number of drugs. The perivenular location of the hepatocellular lesions caused by many drugs, including paracetamol, might reflect the high concentration in zone 3 of the enzymes responsible for the conversion of these drugs into hepatotoxic metabolites [73].
After an episode of acute hepatocellular necrosis, cell debris are phagocytosed by Kupffer cells, which contain Pas-positive diastaseresistant ceroid pigment, often associated with Perls-positive haemosiderin. Only rarely, hepatocytic necrosis may be diffuse, originating bridging necrosis, with severe alterations of the liver architecture.

Another very frequent lesion in drug-related liver disease is steatosis, i.e. fat accumulation inside hepatocytes, appearing as clear droplets different in size, ranging from very small (microvesicular steatosis) to large vacuoles occupying the entire cytoplasm and pushing the nucleus at the cell border (macrovesicular steatosis). Steatosis has been associated with a large number of drugs, together with other forms of liver cell damage, including apoptosis and cell necrosis [74]. Microvesicular steatosis in drug-related liver disease has been mainly associated with fatal salicylate intoxication in children, as a typical finding of the Reye's syndrome [75]. Microvesicular steatosis has been also reported in association with tetracycline hepatotoxicity [76-78]. Macrovesicular steatosis has been observed in DILI due to a large number of drugs, including ibuprofen, indomethacin, paracetamol, rifampicin, sulphasalazine, and zidovudine [79].

Inflammatory lesions may be also present in liver biopsies from children with DILI and, when associated with steatosis, the definition of steatohepatitis may be used. Lymphocytes are the most common inflammatory cells observed in DILI: they are mainly detected in portal tracts and, in some cases, they show adhesion to the membrane of periportal hepatocytes, leading to apoptosis and cell necrosis of the hepatocytes of the periportal lamina, also known as piecemeal necrosis.

The observation, at histology, in DILI of piecemeal necrosis, associated with a dense lymphocytic infiltrate and with plasmacells in clusters, suggests an immunoallergic response. An immunologic mediation of drug-induced hepatitis has been reported with antibiotics, including amoxicillin, clavulanic acid, and sulfonamides [80]. In rare instances, polymorphonuclear cells may also be observed, both in portal tracts and inside the liver acinus.

\section{Liver Disease due to the Most Widely Utilized Drugs in Newborns}

\subsection{Antibiotics}

Due to the high susceptibility to infections of newborns, antibiotics are the most widely utilized drugs in neonates, the best initial therapy against a suspected systemic infection remaining, as several years ago, the association of ampicillin and gentamicin [81]. Moreover, in recent years, antibiotics have been proposed for different indications in the antibacterial activity: erythromicin for the treatment of gastrointestinal dismotility, and for the prevention of cholestasis in preterm infants under parenteral nutrition; azithromycin, because of the combined antibiotic and antiinflammatory effects, in the prevention of bronchopulmonary dysplasia in low birth weight infants [82].

DILI is caused by a wide array of medications, including herbal supplements and dietary supplements, but antibiotics are the single largest class of agents that cause DILI [83]. A recent clinical update on DILI showed that the most common drugs leading to hepatotoxicity in the United States, at every age, are antibiotics [84]. The explanation for the frequent association between antibiotics and hepatotoxicity could be related to the widespread prescription of these drugs, whereas the relative risk of antibioticrelated hepatotoxicity is thought to be low [85]. Multiple mechanisms of antibiotic-induced liver injury have been implicated, including apoptosis activated by TNF-alpha, inhibition of mitochondrial function, and neoantigen formation. In extremely low birth weight infants, prolonged duration of the empirical antibiotic treatment has been associated with increased rates of necrotizing enterocolitis and death [86]. 


\section{$\underline{\text { Penicillins }}$}

Among the penicillins, ampicillin only rarely has been associated with hepatotoxicity [87], but the association amoxicillinclavulanate probably represents the most common cause of cholestasis related to therapy with antibiotics [88, 89], and one of the four most common causes of DILI [85, 90]. This compound is a combination of amoxicillin trihydrate, an aminopenicillin, and potassium clavulanate, a beta-lactamase inhibitor, used to treat a broad-spectrum of bacterial infections, especially resistant strains. Its molecular weight is $564.56 \mathrm{Da}$, and the molecular formula is C24H28N4O10S.

In a study of 153 patients of different ages affected by amoxicillin-clavulanic acid-related hepatitis, liver injury was classified to be hepatocellular in $35(22.8 \%)$, cholestatic in 24 $(15.7 \%)$, and mixed in 83 patients (54.5\%) [91]. In some cases, acute hepatitis showed progression to cirrhosis [92], but in the majority of cases, liver injury was not severe and resolved after prompt withdrawal of the drugs [93, 94]. The incidence of amoxicillin-clavulanate induced hepatotoxicity has been estimated to be 9.9 per 100,000 users, representing between $12.8 \%$ to $14 \%$ of the reported cases of DILI [95]. At histology, hepatocytic and canalicular bilirubinostasis appears to be more pronounced in perivenular regions (zone 3), whereas portal tracts show lymphocytic infiltrate associated with bile duct lesions [96]. Only rare cases of immuno-allergic hepatitis related to amoxicillinclavulanic acid therapy have been reported, all characterized, at liver biopsy, by portal and intraacinar eosinophilic infiltration [97]. The vast majority of cases of DILI related to amoxicillin-clavulanic acid therapy have been reported in adults, even though occasional reports of hepatotoxicity associated with these drugs have also been described in children. In pediatric patients, the adverse effects on liver were characterized by a rapidly progressive liver disease with severe cholestasis due to the necroinflammatory lesions of the intrahepatic bile ducts [98]. In some children, therapy with amoxillin associated to clavulanic acid has been reported to cause the vanishing bile duct syndrome, a liver disease characterized by disappearance of the septal bile ducts in the majority of portal tracts, ending with severe disarrangement of the liver architecture [99]. That is very important to underline, according to many authors amoxicillin-clavulanic acid-related DILI might be underestimated, due to a frequent time interval between stopping the treatment and the first manifestations of liver disease, jaundice in most cases, after discontinuing treatment several weeks [100]. These observations might explain, at least in part, the rarity of reports of adverse effects related to this association in newborns. The frequency of jaundice due to other aetiologies, including immaturity of the bilirubin metabolizing machinery in neonates, particularly in preterms, associated with the absence of a strict relationship between the assumption of these drugs and the insurgence of adverse effects, could be at the basis of an underestimation of their toxicity in the perinatal period. Given that liver disease due to therapy with this association may be severe, and death in patients of different ages have been reported [101], caution should be taken when deciding to start therapy with amoxicillin associated with clavulanic acid in newborns.

\section{Flucloxacillin}

The penicillinase-resistent flucloxacillin ranks as the second highest cause of DILI in many countries [96]. Genetic-association studies have recently identified genotypes related to flucloxacillin hepatotoxicity [85].

\section{Cephalosporins}

In spite of their high efficacy against most of the Gram positive and Gram negative pathogens commonly encountered in neonatal infections, cephalosporins, accordingly with the vast majority of neonatologists, should not be part of the initial empirical therapy in NICU centers, due to their toxicity in newborns [81]. In fact, overuse of cefotaxime in the first three days after birth has been associated with an increased risk of death [102] and neonatal candidiasis, especially in extremely low birth-weight newborns [103]. A reversible symptomatic biliary obstruction associated with ceftriaxone pseudolithiasis is well known to neonatologists [104, 105]. The association of ceftriaxone and calcium-containing solutions in both term and premature infants has been reported to cause fatal reactions, due to calcium-ceftriaxone precipitates in lungs and kidneys. Ceftriaxone should not be utilized in hyperbilirubinemic neonates, especially prematures, given its ability to cause bilirubin displacement, producing an increase of free bilirubin and the decrease of unconjugated bilirubin [106].

\section{Macrolides}

Among macrolides, erythromicin is considered a classical example of drug inducing cholestatic liver disease. Erythromicin causes jaundice in about $1-2 \%$ of adults taking the drug, but only rarely in children [88]. The histological picture of erythromycinrelated DILI is characterized by bilirubinostasis, appearing as bile casts inside dilated bile canaliculi. Cholestatic features are often accompanied by portal lymphocytic infiltrate, with numerous eosinophils [107]. In recent years, concern has arisen regarding telithromycin, a new generation macrolide, frequently associated with severe adverse reactions, characterized by jaundice, fever, abdominal pain and ascites [95].

Azithromicin hepatotoxicity typically causes intrahepatic cholestasis, evidenced at histology by the observation of bilirubinostasis in the cytoplasm of hepatocytes and of bile thrombi inside bile canaliculi [108].

\section{Aminoglycosides}

(e.g. gentamicin, amikacin, netilmicin, tobramicin) are effective antibiotics against Gram-negative infection in neonates, which, in spite of their ototoxicity and nephrotoxicity [109], still remain the frontline antibiotic in developing countries, because of their efficacy and low cost, especially to treat tuberculosis [110].

\section{Gentamicin}

A mainstay in treating Gram-negative sepsis and often combined with a penicillin in NICU clinical practice, only rarely has been associated with hepatotoxicity, no hepatic adverse reactions being observed in the vast majority of treated patients [111]. In mice, gentamicin was found to enhance basal and lipopolysaccharide-stimulated hepatic and renal TNF-alpha mRNA levels, suggesting a possible role in potentiating the inflammatory response, beyond its traditional antimicrobial effect [112]. Recently, a study on gentamicin toxicity carried out in rats by the ingenuity pathway analysis, revealed liver toxicity in the vast majority of animals, along with the previously known kidney and heart toxicity [113]. Gentamicin-related liver toxicity has been hypothesized to be caused by the formation of a toxic metabolite, that localizes to the cytosolic fraction of liver cells [114]. The exposure of preterm and term neonates to toxic serum levels of gentamicin has been also related to the inability to account for the ontogeny of renal function and to adjust dosing regimens according to the actual glomerular filtration rate [115]. Comorbid conditions, such as perinatal asphyxia have been supposed to increase gentamicin toxicity in newborns [116], probably via the caspasedependent cell death pathway [16]. As for the type of cell death caused by gentamicin in liver cells, an electron microscopy study carried out in rats by injecting intramuscularly gentamicin once daily for 1, 2, 3 and 4 weeks successively, clearly showed the ability of gentamicin to induce severe mitochondrial alterations in the hepatocytes, followed by apoptotic cell death [117].

\section{Chloramphenicol}

Has been shown to be highly toxic in the newborn when given in excessive doses, causing a cardiovascular collapse associated 
with the gray syndrome [118]. The explanation of chloramphenicolrelated toxicity is the delayed maturation of the hepatic drugmetabolizing enzymes and, in particular, of glucuronyl transferase [119].

\subsection{Acetaminophen}

Acetaminophen, N-acetil-p-aminophenol, is the active metabolite of phenacetin, widely utilized in clinical practice due to its antipiretic and analgesic properties. Even though it is considered one of the most safe drugs, on the other hand acetaminophen is one of the most common causes of DILI in children [120]. It has been reported to be the most common cause of acute liver disease in children in the United Kingdom and the United States, accounting for $15 \%$ of all drug-induced acute hepatitis [121]. In another study carried out on 417 children younger than 5 years, the incidence of hepatotoxicity due to acetaminophen was $5.5 \%$, as compared with $29 \%$ in adolescents and adults [122]. In the United States, up to $50 \%$ of acetaminophen-related cases of acute liver failure are thought to occur as the result of unintentional overdose [123], leading to the recent decision by the U.S. Food and Drug Administration to limit the dosage of acetaminophen to $325 \mathrm{mg}$ in combination with prescription products.

$\mathrm{N}$-acetil-p-aminophenol undergoes a complex transformation by the liver drug metabolizing system see Fig. (2). $5-15 \%$ of the drug is metabolized by CYP, and in particular by the isoforms $2 \mathrm{E} 1$, $1 \mathrm{~A} 2$ and $3 \mathrm{~A} 4$. This reaction gives rise to $\mathrm{N}$-acetyl-3,4dihydroxyaniline, that may be excreted, and to a toxic compound, $\mathrm{N}$-acetyl-p.benzoquinoneimine (NADPQI), mainly responsible for toxicity and for acute liver disease due to acetaminophen Fig. (2a, 2b). A fraction of acetaminophen, accounting in the adult for 20 $40 \%$, undergoes phase two enzymes transformation, resulting in sulphation and glucuronidation see Fig. (2). The intermediate toxic compound NADPQI may be inactivated by reduced glutathion (GSH), which metabolizes it to mercapturic acid, that may be excreted through urine. In the absence of sufficient cellular stores of $\mathrm{GSH}$, the toxic compound gives rise to covalent bindings with proteins, leading to cell death of hepatocytes and to fulminant hepatitis. Acetaminophen metabolism and elimination kinetics in neonates are markedly different as compared to children and adult subjects, due to the decreased glucuronidation of the drug, a substrate for UGT1A6 and UGT1A9, two isoforms of UGT, peculiar maturational profile of which has relevant pharmacokinetic consequences in drug metabolism in the perinatal period [124]. These age-related differences are attributable to biochemical differences in young children and, in particular, in newborns. In fact, the metabolic profile at birth is characterized by sulphation predominating over glucuronidation, probably contributing to less formation of toxic metabolites Fig. (2b). In addition, neonates have a greater capacity to sinthesize glutathione, thereby inactivating toxic metabolites of acetaminophen more effectively [125]. The last peculiarity of acetaminophen metabolism in newborns, and in particular in preterms, is the low activity of some isoforms of CYP, including CYP2D6 whose values are less than 3-5\% of adult levels at birth. Their scarcely developed activity might be responsible for the minor production of the toxic metabolyte NADPQI, mainly responsible for acute liver disease Fig. (2).

In a retrospective metanalysis carried out on 9,337 patients, including children and adults, undergoing repeated use of therapeutic dosage of acetaminophen, 96 subjects (1.0\%) showed elevated serum levels of aminotransferase, exceeding the upper limit of normal values, one underwent liver transplantation and six $(0.06 \%)$ died of liver failure. On the other hand, prospective studies indicate that true therapeutic acetaminophen dosages may slightly increase serum aminotransferase activity, but do not cause acute liver failure or death, indicating that the reported cases of acute severe (fulminant) liver disease might be related to inadvertent overdose of the drug [126]. In recent years, several cases of acetaminophen-related liver failure have been reported in newborns [127] and in infants [128]. In a study on the causes of 348 cases of acute liver failure in children, acetaminophen toxicity was found to be the most frequent cause of hepatic toxicity, representing $14 \%$ of diagnoses [129]. The severity of acetaminophen-induced acute liver disease in infants and children may be unpredictable, ranging from a slight increase in the serum levels of aminotransferases [126] up to acute hepatic failure, sometimes associated with encephalopathy in newborns $[127,128]$.

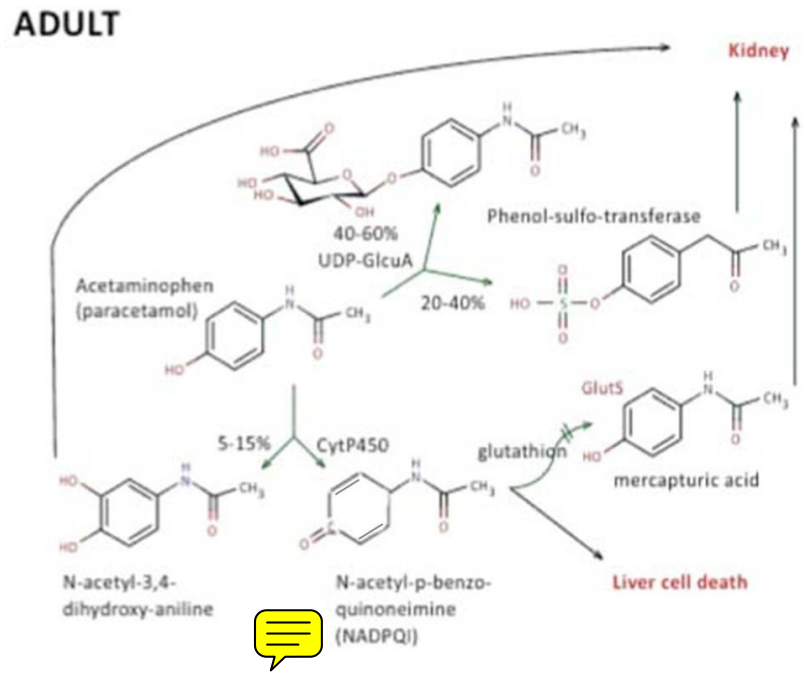

\section{NEWBORN}

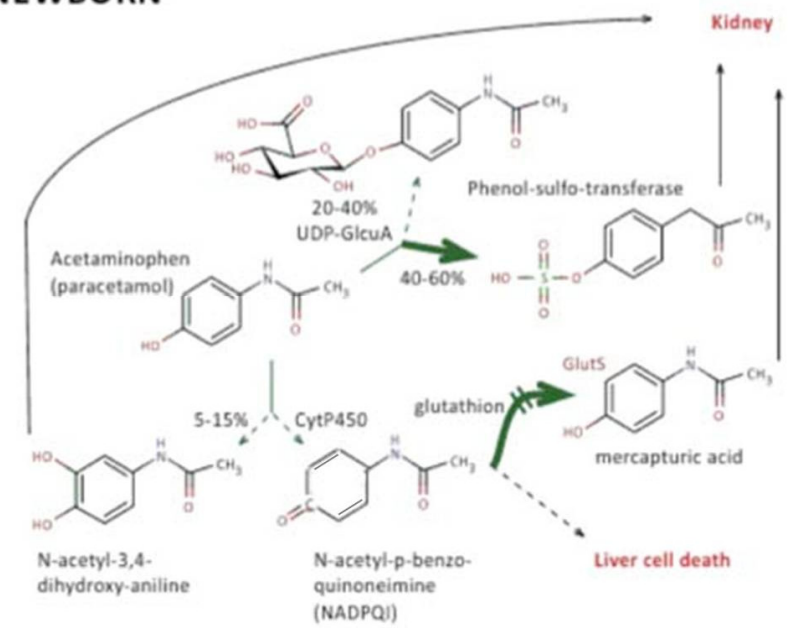

Fig. (2). (a) Metabolism of acetaminophen in the adult. (b) Metabolism of acetaminophen in the newborn.

As for the mechanism of cell death in acetaminophen hepatotoxicity, the mode of cell death in acetaminophen-induced acute liver failure remains controversial. Many authors have claimed that caspase-dependent apoptosis should be considered at the origin of liver disease caused by acetaminophen overdosage $[130,131]$. Other authors did not find any morphological evidence of liver cell apoptosis and, on the contrary, reported liver cell ballooning and necrosis in mice treated with acetaminophen [132]. The histological picture in liver biopsies from patients with acetaminophen-related fulminant hepatitis is characterized by diffuse apoptosis of the vast majority of hepatocytes, also defined as confluent coagulative cell death, responsible for liver failure.

In cases of less severe adverse reaction to acetaminophen, the histological picture of liver biopsy is characterized by zonal hepatocytic cell death, mainly localized in the perivenular areas 
(zone 3). In these patients, the association with epithelioid non caseating granulomas gives a picture very similar to that typically found in sarcoidosis [133].

At histology, combined hepatocellular and cholestatic injury have been reported following acetaminophen intoxication [72]. Recently, acetaminophen has been shown to induce infiltration of liver parenchyma by macrophages derived from circulating monocytes, characterized by the ability to phagocitose apoptotic cells and to cause apoptosis of neutrophils, often characterizing the histological picture of acetaminophen-inducible liver disease [134]. Macrophages and neutrophils have been hypothesized to play opposite roles in acetaminophen-induced liver disease: macrophages produce heme oxygenase, which is thought to have a protective role, whereas neutrophils express indicible nitric oxide synthase (iNOS), which is presumed to be an aggravating molecule for acetaminophen-induced acute liver failure. The balance between these two molecules may determine the outcome of liver disease caused by acetaminophen [135].

The intimate molecular mechanism whereby the drug causes liver cell death has not been completely clarified. Generally, acetaminophen-related liver injury has been included among intrinsic reactions, being dose-dependent and reproducible in experimental animals. Recently, acetaminophen hepatotoxicity has been reported to be enhanced in mice by the inflammatory stress induced by exposure to bacterial lipopolysaccharide (LPS), which significantly lowers the acetaminophen dose sufficient to cause acute liver failure. On the basis of these data, it has been hypothesized that a sporadically occurring inflammatory episode could shift hepatotoxic doses of acetaminophen into the therapeutic range, resulting in a idiosyncratic reaction [67]. The hypothesis that environmental and extrinsic factors might influence liver toxicity of acetaminophen has been recently confirmed by the finding that administration of anti-interleukin-1 antibodies attenuates acetaminophen-induced liver injury, and that administration of recombinant human interleukin-1-receptor antagonist (rhIL-1Ra) could dramatically reduce the death of hepatocytes, increasing survival rate of mice with acute liver failure induced by acetaminophen [130]. Administration of acetaminophen has been shown to induce intrahepatic interferon-gamma expression, leading to hyphotisize that IFN-gamma could be responsible for acetaminophen-induced liver injury, by mediating leukocyte infiltration and hepatocyte cell death [136]. The recent report of acute liver failure as a result of administration of acetaminophen at the maximum recommended daily dose in adults affected by malnutrition and/or low body weight, indicates that some patients may have increased susceptibility to acetaminophen toxicity even to therapeutic doses [137]. Recent data on the efficacy of $\mathrm{N}$ acetylcysteine (NAC) in subjects with acetaminophen-induced liver failure, strongly support the assumption that glutathione deficiency is the crucial point in determining diminished capacity to neutralize $\mathrm{N}$-acetyl-p-benzoquinone imine, leading to massive hepatic cell death [138].

Metabolomics, pharmacogenetics, proteomics and transcriptomics are more recent areas of study that have been applied to for further understanding of DILI. Despite recent advances in our understanding of DILI, many aspects of its pathophysiology and clinical impact remain unclear. In addition, genomic-based studies are evolving concepts, which undoubtedly continue to contribute to our comprehensive understanding of the underlying mechanisms of drug-induced liver injury [139].

New exciting data are derived from metabolomic studies. Metabolomics might therefore be considered analogous to a "liver profile" test in clinical pathology, except that metabolomics includes measurement of metabolites present at much lower concentrations and, accordingly, provides several orders of magnitude greater sensitivity. It seems practicable that, in the more distant future, metabolomics will help genomics to revolutionize and individualize drug therapy [140, 141].

The major pre-drug compounds in the pretreatment of urine that were associated with postacetaminophen hepatotoxicity were taurine, trimethylamine- N-oxide (TMAO), and betaine. The levels of these metabolites were associated with different classes of hepatic histology. NMR-based metabolomic profiles of urine samples collected prior to dosing were found to significantly correlate with the extent of liver injury observed subsequently in each rat (good and poor responders). Metabolic bioactivation, glutathione depletion and covalent binding are the early hallmark events after acetaminophen overdose. Serum metabolomics of acetaminophen-induced hepatotoxicity revealed that the CYP2E1mediated metabolic activation and oxidative stress following acetaminophen treatment can cause irreversible inhibition of fatty acid oxidation, potentially through suppression of PPARr-regulated pathways [34]. Chen et al. identified long-chain acylcarnitines as early biomarkers of acetaminophen- induced hepatotoxicity [142].

Another important aspect in prediction of the response to drugs is linked to the endogenous metabolome from gut bacteria. In a study of healthy human volunteers given a single oral dose of acetaminophen, those with high predose levels of $p$-cresol-sulfate in their urine tended to have reduced urinary elimination of the sulfate metabolite. $p$-Cresol is known to be produced by gut bacteria. The authors concluded that the $p$-cresol coming from the gut via enterohepatic circulation competed with the acetaminophen in the liver for sulfation [143].

Recent toxicological studies have been performed on rats using metabolomics in association with routine clinical chemistry and histopathology. Targeted bile acid analysis, based on LC-MS metabolomics data demonstrated increased levels of conjugated or unconjugated bile acids in response to individual compounds, did not provide earlier detection of toxicity as compared to conventional parameters, but may allow distinction of different types of hepatobiliary toxicity [144].

However, to our knowledge, no data are available, in this field, for newborns, although metabolomics seem very useful for newborns in the next future $[145,146]$.

\subsection{NSAIDS}

Nearly all NSAIDs have been implicated in causing liver injury, comprised the new selective COX-2 inhibitors. Diclofenac and in particular sulindac have been reported to be commonly associated with hepatotoxicity, and several NSAIDs such as ibufenac have been withdrawn due to their liver toxicity [147]. NSAIDs are a heterogeneous group of agents that inhibit synthesis of prostaglandins via blockade of the cyclooxigenase (COX) enzymes. Various NSAIDs are being extensively used in newborns and, in particular, in preterm infants. They are universally used as antipyretics and analgesics in infants, even though the efficacy and safety in neonates have been poorly studied [148]. Intravenous indomethacin and ibuprofen are standard therapies worldwide for closure of patent ductus arteriosus [149, 150]: the mechanism of action of NSAIDs favouring the closure of ductus arteriosus, is related to their ability to inhibit prostaglandin synthesis [151].

The principal target organ of NSAIDs-related toxicity in neonates is kidney, in which prostaglandins, and in particular PGE2, play a homeostatic role through their protective vasodilatory action against the elevated levels of vasoconstrictive angiotensin II that are present in the neonate [152].

Introduced in clinical practice in 1976 for the therapy of patent ductus arteriosus in preterm newborns, indomethacin achieves the closure of ductus arteriosus in $80 \%$ of infants of 28 weeks or more [153]. However, important side effects have been reported, during the years, in newborns treated with indomethacin [154]. Indomethacin has been shown to induce, by a vasoconstrictor 
effect, a significant reduction in cerebral, mesenteric and renal blood flow $[155,156]$. The major consequence of the reduction in mesenteric blood flow is an increased risk of developing necrotizing enterocolitis $[157,158]$. Indomethacin-related liver disease is characterized by steatosis, mainly localized in the perivenular regions (zone 3 of the acinus). Steatosis is, in the majority of cases, macrovesicular and diffused: the vast majority of hepatocytes contain a large cytoplasmic fat droplet that displaces the nucleus to the periphery of the cell [72]. Steatosis is often accompained by liver cell necrosis, which may be zonal or massive and diffused [159]. Rare cases of fulminant hepatitis due to indomethacin have been reported [160], one of them in a child [161].

Due to these side effects of indomethacin, another cyclooxigenase inhibitor, a derivative of ibufenac, ibuprofen, emerged. A large number of randomized studies comparing the two drugs showed the same efficacy for the closure of the patent ductus aretriosus [162, 163]. Moreover, the use of ibuprofen has demonstrated fewer side effects on the renal, mesenteric and cerebral blood flows [164]. However, some cases of pulmonary hypertension have been reported after ibuprofen treatment in very preterm infants [165].

As for hepatotoxicity, ibuprofen has been proven to have a lower incidence of liver disease as compared to indomethacin, even though rare cases of fulminant hepatitis requiring liver transplant have been reported [166]. Two cases of cholestatic hepatitis with bile duct lesions due to ibuprofen, followed by a destructive process of intrahepatic bile ducts ending in vanishing bile duct disease, have been described, one of them in a child $[167,168]$. The prolonged use of ibuprofen has been associated with a higher risk of enterocolitis and with changes in renal function [169]. Dramatic reduction in urinary PGE2 concentrations after ibuprofen treatment has been described in preterm infants with patent ductus arteriosus [152].

\subsection{Acetylsalicilic Acid}

Acetylsalicylic acid first undergoes transformation in blood, where it is metabolized to salicylic acid by ASA-esterase see Fig. (2). In the hepatocyte, salicylic acid undergoes complex biotransformations, by phase 1 and phase 2 enzymes. In particular, CYP enzymes give rise to hydroxylation, with formation of 2,3 and 2,5 dyhydroxy benzoic acid, which are metabolized to hydroquinone and catecol, two highly hydrophilic compounds which are easily excreted through urine. Another fraction of salycilic acid undergoes glycine conjugation, giving rise to salyciluric acid. A third fraction of salycilic acid ingested undergoes glucuronidation by UDP, giving rise to glucuronide acylic and glucuronide phenolic Fig. (3a). The peculiarities of the drug metabolizing system at birth, are responsible for a peculiar metabolism of acetylsalicylic acid in the neonate Fig. (3b): this is characterized by the prevalence of enzymes deputed to glycine conjugation, responsible for the higher production of salyciluric acid, and by decreased production of CYP enzymes and of UDP Fig. (3b).

Liver disease associated with aspirin therapy is, in the vast majority of cases, clinically mild and reversible, with hepatocellular damage revealed by increased AST/ALT serum levels and bilirubin levels mildly elevated, jaundice being present in less than $5 \%$ of affected individuals [170]. Liver biopsy shows the presence of a mild lymphomonocytic infiltrate in portal tracts, associated with foci of intralobular liver cell necrosis [171]. The mechanism of acetylsalicylic acid hepatotoxicity might be due to the saturation, in children, of the major metabolic pathways leading to transformation of acetylsalicylic acid into salicyluric and salicylphenolic glucuronide, followed by the accumulation of minor metabolites, that could be the responsible for hepatic injury and liver disease [170]. In children affected by viral infections, including influenza and varicella, the acetylsalicylic acid use has been associated with the insurgence of Reye syndrome, characterized by diffuse and severe microvesicular steatosis, associated with encephalopathy [172-174]. Even though the intimate mechanism by which aspirin interacts with the viral infection to cause the diffuse microvesicular steatosis and encephalopathy is, at the best of our knowledge, unexplained, the main physiopathological hypothesis is a mitochondrial metabolism insult, eventually causing acute liver failure and liver transplantation [175]. On the basis of these data, the use of aspirin in children under 12 affected by viral infection has been banned in the United Kingdom since 1986 [176] and warnings about use of salicylates in children with influenza or varicella have led to a sharp decline in the number of children reported to have Reye's syndrome, which is now very rare [177, 173]. According to a recent article on Reye's syndrome, it remains little-known, the causes of the disease are still unclear, and it can still not be proved irrefutably whether administration of acetylsalicylic acid is a factor in the development of Reye's syndrome [172].
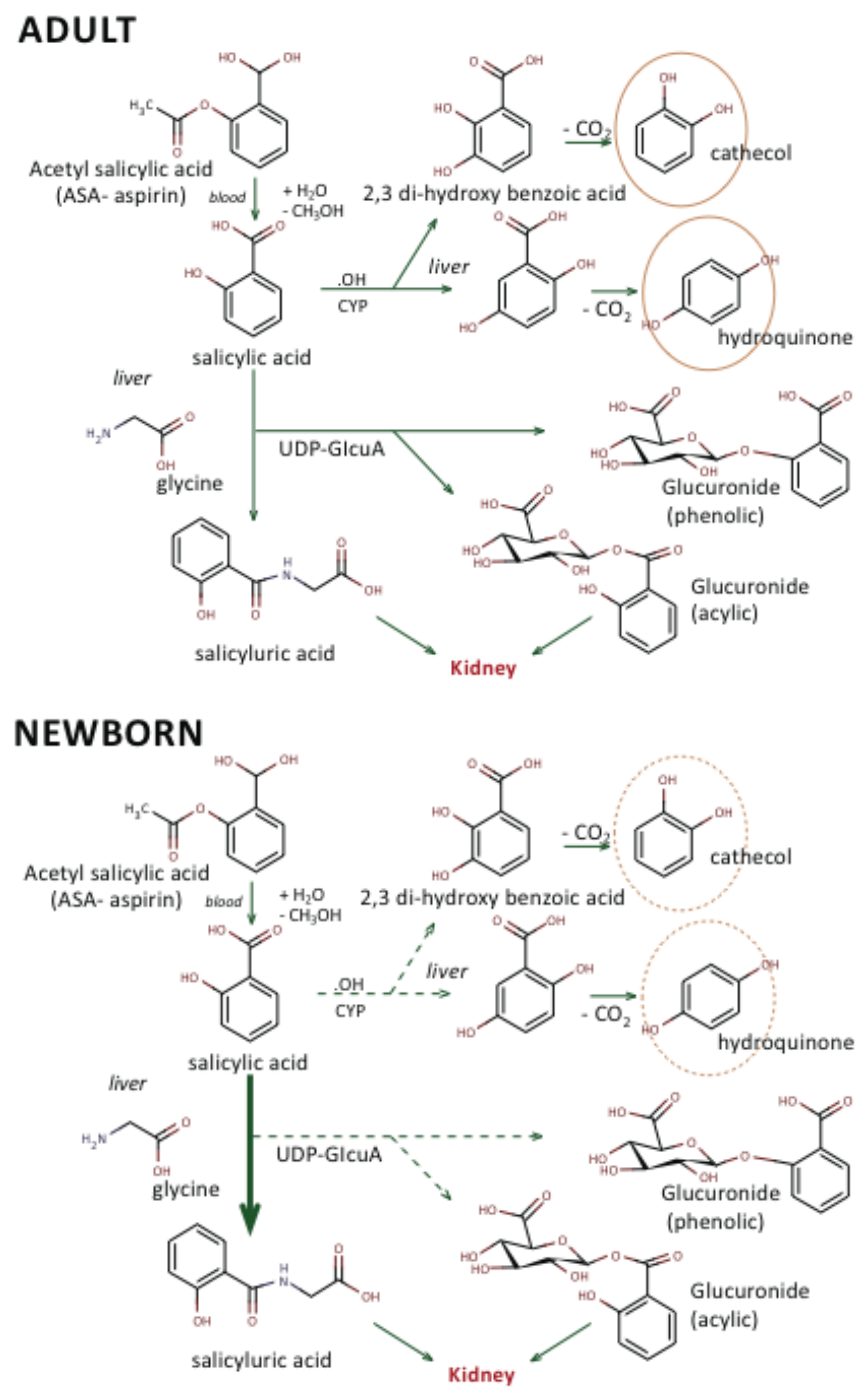

Fig. (3). (a) Metabolism of acetylsalicilic acid in the adult. (b) Metabolism of acetylsalicylic acid in the newborn.

\section{Antiepilectic Drugs}

Pharmacokinetic differences between neonates, children and adults have been reported to affect the absorption, distribution, metabolism and excretion of antiepileptic drugs, like many other drugs [8]. 
Valproic acid (VPA) therapy has been reported to be associated with liver disease, revealed by elevation of liver function tests in $15-30 \%$ of patients, most cases occurring in children younger than 2 years. VPA-related hepatotoxicity was associated with an increase in the formation of oxidative metabolites in children, compared with adults $[178,179]$. While in the vast majority of cases elevation of serum levels of transaminases is a transient phenomenon, occasional cases of fulminant hepatitis following VPA therapy have been reported [180,181], predominantly in young children [182]. The histological picture of VPA-related liver disease is characterized by diffuse microvesicular steatosis associated with apoptosis and lytic necrosis of hepatocytes, in the absence of significant signs of inflammation. Many hypotheses have been proposed during the years regarding the pathogenesis of the hepatotoxicity of VPA, including preexisting mitochondrial disease [183], associated inborn metabolic defects [184], inhibition of mitochondrial beta-oxidation [185], and toxicity from the unsaturated metabolites 4-ene-VPA and 2,4-diene-VPA [186]. A study on the serum metabolite pattern of VPA infants under therapy with the drug, revealed higher concentration ratios of 4-ene-VPA to VPA [187]. Moreover, the formation of the hepatotoxic metabolite of VPA increased in patients under polytherapy with phenytoin, carbamazepine, and stiripentol [188].

Valproate has been also associated with the hypersensitivity syndrome described in children under therapy with the anticonvulsant lamotrigine (LTG) $[189,190]$. VPA could inhibit the UGT1A4-catalyzed formation of LTG- glucuronide, resulting in an increased CYP-dependent formation of the toxic metabolite arene oxide intermediate, mainly responsible for the idiosyncratic reaction to LTG [191].

Phenobarbital, despite its widespread use in NICU as an anticonvulsant and as enzyme inducer, has been associated only rarely to drug-related liver disease. Only one case of massive hepatic necrosis after administration of phenobarbital has been reported, to the best of our knowledge, in the literature [192].

\section{Miscellanea}

Nevirapine, a non-nucleoside inhibitor of human immunodeficiency virus type- 1 reverse transcriptase, is used in highly active antiretroviral therapy combination regimens for the treatment of HIV infection and, in particular, for the prevention of mother-to-child HIV transmission [193]. Nevirapine antiretroviral therapy has been frequently associated with the insurgence of severe hepatotoxicity, including cases of fulminant hepatitis with liver failure [194]. Major adverse reactions, including hepatotoxicity, occur in approximately $3 \%$ of HIV-infected individuals who receive long-course nevirapine-containing regimens, with higher rates being noted among females [195]. Short-course nevirapine for HIV prophylaxis is associated with fewer hepatotoxic reactions for HIV-infected women and their offspring, but administration for more than two weeks is associated with higher rates of liver toxicity in pregnant mothers and in their children [196]. The histological picture of liver disease related to nevirapine toxicity was chracterized, in cases with good prognosis, by cholestasis with bile canalicular plugs, mainly concentrated in the zone 3 of the liver acinus, associated with portal infiltrate of eosinophils, in the absence of significant hepatocellular necrosis [194]. In rare cases, liver biopsy revealed the presence of extensive liver cell necrosis, extending from the periterminal areas (zone 3 of the acinus) towards the portal tracts, giving rise to bridging necrosis, asociated with portal infiltration by eosinophils and lymphocytes, clinically corresponding to fulminant hepatitis [196].

Methanphetamine, better known as ectasy, is one of the fastest growing illicit drugs in United States and in Europe. It has been recognized as a common cause of severe acute drug-related hepatitis in adults [197]. The clinical picture is characterized, in the vast majority of patients, by a strict similarity to the typical acute viral hepatitis [198], even though a marked variability in the clinical expression of ectasy-induced liver disease has been reported [199]. In rare cases, the use of methanphetamine has been recognized as the main cause of fulminant hepatitis [200]. Recently, prenatal exposure to methanphetamine has been identified as the cause of acute hepatitis with severe bilirubinostasis in a newborn born to a mother dependent on drugs, and with positivity for methanphetamine test in the urine [201].

\section{CONCLUSIONS}

Dosing, timing, and route of administration must take in careful consideration the marked variability of neonates, particularly of preterms and of low birth weight newborns, regarding bioavailability, distribution, metabolism, biotransformation and excretion to achieve the maximum efficacy and limit the always possible adverse effects [202]. Developmental changes in liver xenobiotics' metabolism, and in particular in drug metabolism, should be considered as a major factor responsible for the marked differences in drug-related hepatotoxicity between newborns, children and adults. The peculiar frequency and degree of hepatotoxicity from many drugs in neonates may be easily explained by an imbalance between the generation of toxic metabolites in the hepatocytes, and the immaturity at birth of the detoxification processes.

In summary, drug metabolism in neonates shows many peculiarities and marked differences as compared to the hepatic metabolism in adults. This appears to be mainly due to the immaturity at birth, and in particular in preterm newborns, of the hepatic drug metabolizing system. This immaturity results in the accelerated metabolization and excretion of some drugs, and in the decreased metabolization of other drugs, with significant consequences in clinical practice. The evidences on the rapid maturation of the different drug metabolizing enzymes during the perinatal period are at the basis of continuous changes, day by day, in the ability to metabolize drugs in the same neonate, adding new difficulties regarding the decisions taken on dosing of each drug employed. All these data clearly indicate personalized medicine as the main target of any neonatologist, considering the interindividual variability in the maturity of the drug metabolizing system, even among subjects showing the same gestational age at birth.

Finally, we want to emphasize the need for educational initiatives in NICU centers aimed at increasing the neonatologists' awareness of the usefulness and the limitations of the widely used drugs in the neonate, and at favouring appropriate risk comunication strategies in order to avoid both adverse liver effects and unjustified interruption of therapies. Multicenter referral networks enrolling children with suspected DILI according to standardized methodologies are needed. These networks should also provide crucial insights into the mechanism(s) of DILI, with the ultimate aim of preventing future cases of drug-related hepatitis and drug-related deaths in the newborn.

\section{CONFLICT OF INTEREST}

The author(s) confirm that this article content has no conflicts of interest.

\section{ACKNOWLEDGEMENT}

Declared none.

\section{REFERENCES}

[1] Lammert, C.; Bjornsson, E.; Niklasson, A.; Chalasani, N. Oral medication with significant hepatic metabolism at higher risk for hepatic adverse events. Hepatology, 2010, 51, 615-620.

[2] Suzuki, A.; Andrade, G.J.; Bjornsson, E.; Lucena, M.I.; Lee, W.M.; Yuen, 
N.A.; Hunt, C.M.; Freston, J.W. Drugs associates with hepatotoxicity and their reporting frequency of liver adverse events in VigiBase: unified list based on international collaborative work. Drug Saf., 2010, 33, 503-522.

[3] Rockey, D.C.; Seeff, L.B.; Rochon, J.; Freston, J.; Chalasani, N.; Bonacini, M.; Fontana, R.J.; Hayashi, P.H.; for the US Drug-Induced Liver Injury Network. Causality assessment in drug-induced liver injury using a structured expert opinion process: comparison to the Roussel-Uclaf causality assessment method. Hepatology, 2010, 51, 2117-2126.

[4] Lewis, J.H. Drug-induced liver disease. Med. Clin. North Am., 2000, 84, 1275-1311.

[5] Lee, W.M. Drug-induced hepatotoxicity. N. Engl. J. Med., 2003; 349, 474485 .

[6] Morselli, PL. Clinical pharmacokinetics in neonates. Clin. Pharmacokinet., 1976, 1(2), 81-98.

[7] De Gregori, S.; De Gregori, M.; Ranzani, G.N.; Borghesi, A.; Regazzi, M.; Stronati, M. Drug transporters and renal drug disposition in the newborn. $J$. Maternal-Fetal Neonatal Med., 2009, 22 (Suppl 3), 31-37.

[8] Anderson, G.D. Children versus adults: pharmacokinetic and adverse-effect differences. Epilepsia, 2002, 43(Supp1 3), 53-59.

[9] Dutton, G.J. Developmental aspects of drug conjugation with special reference to glucuronidation. Annu. Re.v Pharmacol Toxicol., 1978, 18, 1735 .

[10] Cummings, A.J.; Whitelaw, A.G. A study of conjugation and drug elimination in the human neonate. Br. J. Clin. Pharmacol., 1981, 12, 511515 .

[11] Kearns, G.L. Pharmacogenetics and development: are infants and children at increased risk for adverse outcomes? Curr. Opin. Pediatr., 1995, 7, 220-233.

[12] Kearns, G.L.; Abdel-Rahman, S.M.; Alander, S.W.; Blowey, D.L.; Leeder, J.S.; Kauffman, R.E. Developmental pharmacology- Drug disposition, action, and therapy in infants and children. N. Engl. J. Med., 2003, 349, 1157-1167.

[13] Ceelie, I.; van der Starre, C.; Tibboel, D.; Stol, K.; Koren, G.; de Wildt, S.N. Evaluation of drug formularies for pediatric intensive care. Pediatr. Crit. Care Med., 2011, 12, e14-e19.

[14] Dispersyn, G.; Chassard, D.; Pain, L. Biological rythms for anaesthesia and intensive care. Ann. Fr. Anesth. Reanim., 2010, 29, 470-477.

[15] Potts, A.L.; Cheeseman, J.F.; Warman, G.R. Circadian rythms and their development in children: implications for pharmacokinetics and pharmacodynamics in anesthesia. Paediatr. Anaesth., 2011, 21, 238-246.

[16] Lin, C.D.; Kao, M.C., Tsai MH, Lai CH, Wei IH, Tsai MH, Tang CH, Lin $\mathrm{CW}$, Hsu CJ, Lin CY. Transient ischemia/hypoxia enhances gentamicin ototoxicity via caspase-dependent cell death pathway. Lab. Invest., 2011, 91, 1092-1106.

[17] Filippi, L.; la Marca, G.; Cavallaro, G.; Fiorini, P.; Favelli, F.; Malvagia, S.; Donzelli, G.; Guerrini, R. Phenobarbital for neonatal seizure in hypoxic ischemic encephalopathy: a pharmacokinetic study durino whole body hypothermia. Epilepsia, 2011, 52, 794-801

[18] Filippi, L.; la Marca, G.; Fiorini, P.; Poggi, C.; Cavallaro, G.; Malvagia, S.; Pellegrini-Giampietro, D.E.; Guerrini, R. Topiramate concentrations in neonates treated with prolonged whole body hypothermia for hypoxic ischemic encephalopathy. Epilepsia, 2009, 50, 2355-2361.

[19] Piekarczyk A, Kaminska E, Taljanski W, Sosonowska K, Poszwinska B, Rutkowska M. Pharmacokinetics of netalmicin in neonates. Med. Wieku. Rozwoj., 2003, 7(4 Pt 2), 547-555.

[20] Anderson, B.J. Developmental pharmacology; filling one knowledge gap in pediatric anesthesiology. Paediatr. Anaesth., 2011, 21(3), 179-182.

[21] Stewart, C.F.; Hampton, E.M. Effect of maturation on drug disposition in pediatric patients. Clin. Pharm., 1987, 6, 548-564.

[22] Morselli, P.L.; Franco-Morselli, R.; Bossi, L. Clinical pharmacokinetics in newborns and infants: age-related differences and therapeutic implications. Clin. Pharmacokinet., 1980; 5, 485-527.

[23] Yokoi, T. Essentials for starting a pediatric clinical study (1): pharmacokinetics in children. J. Toxicol. Sci., 2009, 34, SP307-SP312.

[24] Ueshima ,S.; Aiba, T.; Ishikawa, N.; Sato, T.; Kawasaki, H.; Kurosaki, Y.; Ohtsuka, Y.; Sendo, T. Poor applicability of estimation method for adults to calculate unbound serum concentrations of valproic acid in epileptic neonates and infants. J. Clin. Pharm. Ther., 2009, 34, 415-422.

[25] Bartelink, I.H.; Rademaker, C.M.; Schobben, A.F.; van den Anker, J.N. Guidelines on pediatric dosing on the basis of developmental physiology and pharmacokinetic considerations. Clin. Pharmacokinet., 2006, 45, 1077-1097.

[26] Bohan, A.; Boyer, J.L. Mechanisms of hepatic transport of drugs: implications for cholestatic drug reactions. Semin. Liver. Dis., 2002, 22, 123 136.

[27] Pauli-Magnus, C.; Meier, P.J. Hepatobiliary transporters and drug-induced cholestasis. Hepatology, 2006, 44, 778-787.

[28] Buratti, S.; Lavine, J.E. Drugs and the liver: advances in metabolism, toxicity, and therapeutics. Curr. Opin. Pediatrics, 2002, 14, 601-607.

[29] Padda, M.S.; Sanchez, M.; Akhtar, A.J.; Boyer, J.L. Drug-induced cholestasis. Hepatology, 2011, 53, 1377-1387.

[30] Farrell, G.C. In: Sleisenger \& Fordtran's Gastrointestinal and liver disease; Feldman M, Friedman LS, Sleisenger MH, Eds.; WB Saunders: Philadelphia, 2002, pp. 1403-1447.

[31] DeLeve, L.D.; Kaplowitz, N. Mechanisms of drug-induced liver disease. Clin. Liver. Dis., 2002, 6, 755-774.

[32] Morselli, P.L. Influence of growth on the pharmacokinetics of drugs in the newborn infants, infants, and children. Ann. Pediatr., 1986, 33, 151-160.

[33] Besunder, J.B.; Reed, M.D.; Blumer, J.L. Principles of drug biodisposition in the neonate. A critical evaluation of the pharmacokinetic-pharmacodynamic interface (Part II). Clin. Pharmacokinet., 1988, 14, 261-286.

[34] Korrinthenberg, R.; Haug, C.; Hannak, D. The metabolization of carbamazepine to CBZ-10,11-epoxide in children from the newborn age to adolescence. Neuropediatrics, 1994, 25, 214-216.

[35] de Wildt, S.N.; Kearns, G.L.; Leeder, J.S.; van den Anker, J.N Glucuronidation in humans: pharmacogenetic and developmental aspects. Clin. Pharmacokinet., 1999, 36, 439-452.

[36] Anderson, G.D.; Lynn, A.M. Optimizing pediatric dosing: a developmental pharmacologic approach. Pharmacotherapy, 2009, 29, 680-690.

[37] Pineiro-Carrero, V.M.; Pineiro, E.O. Liver. Pediatrics, 2004, 113, 1097 1106.

[38] Seaton, M.J.; Schlosser, P.; Medinsky, M.A. In vitro conjugation of benzene metabolites byhuman liver: potential influence of interindividual variability on benzene toxicity. Carcinogenesis, 1995, 16, 1519-1527.

[39] Fanos, V.; Yurdakök, M. Personalized neonatal medicine. J. Maternal-Fetal Neonatal Med., 2010, 23, 4-6.

[40] Klinger, W. Biotransformation of drugs and other xenobiotics during postnatal development. Exp. Toxicol. Pathol., 1996, 48 (Suppl 1), 1-88.

[41] Nelson, D.R.; Kamataki, T.; Waxman, D.J.; Guengerich, F.P.; Estabrook, R.V.; Feyereisen, R.; Gonzalez, F.J.; Coon, M.J.; Gunsalus, I.C. DNA and Cell Biology, 1993, 12, 1-51.

[42] Oinonen, T.; Lindros, K.O. Zonation of hepatic P-450 expression and regulation. Biochem. J., 1998, 329, 17-35.

[43] Hines, R.N.; McCarver, D.G. The ontogeny of human drug metabolizing enzymes: phase I oxidative enzymes. J. Pharmacol. Exp. Ther, 2002, 300, 355-360.

[44] Anzenbacher, P.; Anzenbacherova, E. Cytochromes P 450 and metabolism of xenobiotics. Cell. Mol. Life Sci., 2001, 58, 737-747.

[45] Wrighton, S.A.; Stevens, J.C. The human hepatic cytochrome P450 involved in drug metabolism. Crit. Rev. Toxicol., 1992, 22, 1-21.Stevens JC, Marsh SA, Zaya MJ, Regina KJ, Divakaran K, Le M, Hines RN. Developmental changes in human liver CYP2D6 expression. Drug Metabolism and Disposition, 2008, 36, 1587-1593

[47] Shimada, T.; Yamazaki, H.; Mimura, M.; Inui, Y.; Guengerich, F.P. Interindividual variations in human liver cytochrome P-450 enzymes involved in the oxidation of drugs, carcinogens and toxic chemicals: studies with liver microsomes of 30 japanese and 30 caucasians. J. Pharmacol. Exp. Ther., 1994, 270, 414-423.

[48] Treluyer, J.M.; Sonnier, M. et al. Evidence of impaired cisapride metabolism in neonates. Br. J. Clin. Pharmacol., 2001, 52, 419-425.

[49] Strassburg, C.P.; Strasburg, A.; Kneip, S.; Barut, A.; Tukey, R.H.; Rodeck, B.; Manns, M.P. Developmental aspects of human hepatic drug glucuronidation in young children and adults. Gut, 2002, 50, 259-265.

[50] Nathanson, M.H.; Boyer, J.L. Mechanisms and regulation of bile formation. Hepatology, 1991, 14, 551-566.

[51] Bjornsson, E.; Olsson, R. Outcome and prognostic markers in severe druginduced liver disease. Hepatology, 2005, 42, 481-489.

[52] Geubel, A.P.; Sempoux, C.L. Drug and toxin-induced bile duct disorders. $J$. Gastroenterol. Hepatol., 2000, 15, 1232-1238.

[53] Desmet, V.J. Ductal plates in hepatic ductular reactions. Hypothesis and implications. II. Ontogenic liver growth in childhood. Virchows Archiv: an international journal of pathology, 2011, 458(3), 261-70.

[54] Zhou, S.F.; Liu, J.P.; Chowbay, B. Polymorphism of human cytochrome P450 enzymes and its clinical impact. Drug Metab. Rev., 2009, 41, 289-295.

[55] Maeda K, Sugiyama Y. Impact of genetic polymorphism of transporters on the pharmacokinetic, pharmacodynamic and toxicological properties of anionic drugs. Drug Metab. Pharmacokinet., 2008, 23, 223-235.

[56] Ma, J.D.; Nafziger, A.N.; Bertino, J.S. Jr. Genetic polymorphisms of cytochrome $\mathrm{P} 450$ enzymes and the effect on interindividual, pharmacokinetic variabilitu in extensive metabolizers. J. Clin. Pharmacol., 2004, 44, 447-456.

[57] Bradford, L.D. CYP2D6 allele frequency in european caucasians, asians, africans and their descendents. Pharmacogenomics, 2002, 3, 229-243.

[58] Court, M.H.; Duan, S.X.; Moltke, L.L.; Greenblatt, D.J.; Patten, C.J.; Miners, J.O.; Mackenzie, P.I. Inter individual variability in acetaminophen glucuronidation by human liver microsomes: identification of relevant acetaminophen UDP-glucuronosyltransferase isoforms. J. Pharmacol. Exp. Ther, 2001, 299, 998-1006.

[59] Fontana, R.J.; Seeff, L.B.; Andrade, R.J.; Björnsson, E.; Day, C. P.; Serrano, J.; Hoofnagle, J. H. Standardization of nomenclature and causality assesment in drug-induced liver injury: summary of a clinical research workshop. Hepatology, 2010, 52, 730-742

[60] Bjornsson, E.S. Drug-induced liver injury. Laeknabladid, 2010, 96: 175-182.

[61] Rockey, D.C.; Seeff, L.B.; Rochon, J. Causality assessment in drug-induced liver injury using astructured expert opinion process: comparison to the Roussel-Uclaf causality assessment method. Hepatology, 2010, 51: 21172126.

[62] Liss, G.; Lewis, J.H. Drug-induced liver injury:what was new in 2008 ? Expert Opin. Drug Metab. Toxicol., 2009, 5, 843-860.

[63] Assis, D.N.; Navarro, V.J. Human drug hepatotoxicity: a contemporary clinical prospective. Expert Opin. Drug Metab. Toxicol., 2009, 5, 463-473.

[64] Fontana, R.J.; Watkins, P.B.; Bonkovsky, H.L.; Watkins, P.B.; Davern, T.; Serrano, J.; Yang, H.; Rochon, J. Drug-Induced Liver Injury Network 
(DILIN) prospective study: rationale, design and conduct. Drug Saf., 2009, 32, 55-68.

[65] Lammert, C.; Einarsson, S.; Saha, C.; Niklasson, A.; Bjornsson, E.; Chalasani, N. Relationship between daily dose of oral medications and idiosyncratic drug-induced liver injury: search for signals. Hepatology, 2008; 47, 2003-2009.

[66] Bjornsson, E. The natural history of drug-induced liver injury. Semin. Liver. Dis., 2009, 29, 357-363.

[67] Roth, R.A.; Ganey, P.E. Intrinsic versus idiosyncratic drug-induced hepatotoxicity: two villains or one? J. Pharmacol. Exp. Ther, 2010, 332, 692-697.

[68] Grunhage F, Fischer HP, Sauerbruch T, Reichel C. Drug- and toxin-induced hepatotoxicity. Z Gastroenterol., 2003, 41, 565-578.

[69] Karpen, S.J.; Suchy, F.J. In: Liver Disease in children; Lippincot Williams \& Wilkins Co.: Philadelphia, 2001, pp. 3-21.

[70] Faa, G.; Ambu, R.; Congiu, T.; Costa, V.; Ledda-Columbano, G.M.; Coni, P.; Curto, M.; Giacomini, L.; Columbano, A. Early ultrastructural changes during thioacetamide-induced apoptosis in rat liver. J. Submicrosc. Cytol. Pathol., 1992, 24, 417-424.

[71] Reed, D.J. In: Toxicology of the Liver; Plaa GL, Hewitt WR, Eds.; Taylor and Francis Co: Washington, 1998, pp. 221-257.

[72] Lewis, J.H.; Kleiner, D.E. In: MacSween's Pathology of the Liver; Burt, A.D.; Portmann, B.C.; Ferrell, L.D.; Ed.; Churchill Livingstone: Philadelphia, 2007, pp.649-759.

[73] Mitchell, J.R.; Jollow, D.J.; Potter, W.Z. Acetaminophen-induced hepatic necrosis. I. Role of drug metabolism. J. Pharmacol. Exp. Ther., 1973, 187, 185-194.

[74] Zimmerman, H.J. Effects of aspirin and acetaminophen on the liver. Arch. Intern. Med., 1981, 141, 333-342.

[75] Starko, K.M.; Mullick, F.G. Hepatic and cerebral pathology findings in children with fatal salicylate intoxication: further evidence for a causal relation between salicylate and Rey's syndrome. Lancet, 1983, i, 326-329.

[76] Schenker, S.; Breen, K.J.; Heimberg, M. In: Pathogenesis of tetracycline induced fatty liver; Gerok, W.; Sickinger, K. Eds.; FK Schattauer-Verlag Co.: Stuttgart, 1972, pp. 269-280.

[77] Anthèrieu, S.; Rogue, A.; Fromenty, B.; Guillouzo, A.; Robin, M.A. Induction of vesicular steatosis by amiodarone and tetracycline is asociated with up-regulation of lipogenic genes in HepaRG cells. Hepatology, 2011, 53(6), 1895-1905

[78] Eadie, M.J.; Hooper, W.D.; Dickinson, R.G. Valproate-associated hepatotoxicity and its biochemical mechanisms. Med. Toxicol. Adverse Drug Exp., 1988, 3, 85-105.

[79] Kleiner, D.E. The pathology of drug-induced liver injury. Semin. Liver. Dis., 2009, 29, 364-372.

[80] Furst, S.M.; Gandolfi, A.J. In: Toxicology of the Liver; Plaa, G.L.; Hewitt, W.R. Eds.; Taylor and Francis Co.: Washington, 1998, pp. 259-296.

[81] Chirico, G.; Barbieri, F.; Chirico, C. Antibiotics for the newborn. $J$. Maternal-Fetal Neonat. Med., 2009, 22, 46-49.

[82] Ballard, H.O.; Shook, L.A.; Bernard, P.; Anstead, M.I.; Kuhn, R.; Whitehead, V.; Grider, D.; Crawford, T.N.; Hayes, D. Jr. Use of azithromycin for the prevention of bronchopulmonary dysplasia in preterm infants: a randomized, double blind, placebo controlled trial. Pediatr. Pulmonol., 2011, 46, 111-118.

[83] Chalasani, N.; Fontana, R.J.; Bonkovsky, H.L.; Watkins, P.B.; Davern, T.; Serrano, J.; Yang, H.; Rochon, J. Drug Induced Liver Injury Network (DILIN). Causes, clinical features, and outcomes from a prospective study of drug-induced liver injury in the United States. Gastroenterology, 2008, 135, 1924-1934.

[84] Ghabril, M.; Chalasani, N.; Bjornsson, E. Drug-induced liver injury: a clinical update. Curr. Opin. Gastroenterol., 2010; 26, 222-226.

[85] Robles, M.; Toscano, E.; Cotta, J.; Lucena, M.I.; Andrade, R.J. Antibioticinduced liver toxicity: mechanisms, clinical features and causality assessment. Curr. Drug Saf., 2010, 5, 212-222.

[86] Cotten, C.M.; Taylor, S.; Stoll, B.; Goldberg, R.N.; Hansen, N.I.; Sánchez, P.J.; Ambalavanan, N.; Benjamin, D.K. Jr.; NICHD Neonatal Research Network. Prolonged duration of empirical antibiotic treatment is associated with increased rates of necrotizing enterocolitis and death for extremely low birth weight infants. Pediatrics, 2009, 123, 58-66.

[87] Zimmerman, H.J. Effects of aspirin and acetaminophen on the liver. Arch. Intern. Med., 1981, 141, 333-342.

[88] Lewis, J.H.; Zimmerman, H.J. Drug- and chemical-induced cholestasis. Clin Liver. Dis., 1999, 3, 433-464.

[89] Cundiff, J.; Joe, S. Amoxicillin-clavulanic acid-induced hepatitis. Am. J. Otolaryngol., 2007, 28, 28-30.

[90] Reuben, A. Needles in haystacks. Am. J. Gastroenterol., 2007, 102, $2444-$ 2446.

[91] Gresser, U. Amoxicillin-clavulanic acid therapy may be associated with severe side effects- review of the literature. Eur. J.Med. Res., 2001, 20, 139149.

[92] Jordan, T.; Gonzàles, M.; Casado, M.; Suárez, J.F.; Pulido, F.; Guerrero, E.; Esteban, J. Amoxicillin-clavulanic acid induced hepatotoxicity with progression to cirrhosis. Gastroenterol. Hepatol., 2002, 25, 240-243.

[93] Hartleb, M.; Biernat, L.; Kochel, A. Drug-induced liver damage- a three-year study of patients from one gastroenterological department. Med. Sci. Monit., 2002, 8, CR292-CR296.
[94] Zaidi, S.A. Hepatitis associated with amoxicillin-clavulanic acid and/or ciprofloxacin. Am. J. Med. Sci., 2003, 325, 31-33.

[95] Robles, M.; Andrade, R.J. Hepatotoxicity by antibiotics: update in 2008. Rev. Esp. Ouimioter., 2008, 21, 224-233.

[96] Hautekeete, M.L. Hepatotoxicity and antibiotics. Acta Gastroenterol. Belg., 1995, 58, 290-296.

[97] Breuskin, F.; Horsmans, Y.; Rahier, J.; Lambert, M. Recurrent immunoallergic hepatitis related to amoxicillin-clavulanic acid. Acta Clin. Belg. 2001, 56, 255-257.

[98] Chawla, A.; Kahn, E.; Yunis, E.J.; Daum, F. Rapidly progressive cholestasis: an unusual reaction to amoxicillin/clavulanic acid therapy in a child. $J$. Pediatr., 2000, 136, 121-123.

[99] Smith, L.A.; Ignacio, J.R.; Winesett, M.P.; Kaiser, G.C.; Lacson, A.G.; Gilbert-Barness, E.; Gonzàles-Peralta, R.P.; Wilsey, M.J. Jr. Vanishing bile duct syndrome: amoxicillin-clavulanic acid associated intra-hepatic cholestasis responsive to ursodeoxycholic acid. J. Pediat.r Gastroenterol. Nutr., 2005, 41, 469-473.

[100] Mari, J.Y.; Guy, C.; Beyens, M.N.; Ollagnier, M. Delayed drug-induced hepatic injury. Evoking the role of amoxicillin-clavulanic acid combination. Therapie, 2000, 55, 699-704.

[101] Gresser, U. Amoxicillin-clavulanic acid therapy may be associated with severe side effects- review of the literature. Eur. J. Med. Res., 2001, 6, 139149.

[102] Clark, R.H.; Bloom, B.T.; Spitzer, A.R.; Gerstmann, D.R. Empirical use of ampicillin and cefotaxime, compared with ampicillin and gentamicin, for neonates at risk for sepsis is associated with an increased risk of neonatal death. Pediatrics, 2006, 117, 67-74.

[103] Cotten, C.M.; McDonald, S.; Stoll, B.; Goldberg, R.N.; Poole, K.; Benjamin, D.K. Jr. The association of third-generation cephalosporin use and invasive candidiasis in extremely low birth-weight infants. Pediatrics, 2006, 118 717-722.

[104] Zinberg, J.; Chernaik, R.; Coman, E.; Rosenblatt, R.; Brandt, L.J. Reversible symptomatic biliary obstruction associated with ceftriaxone pseudolithiasis Am. J. Gastroenterol., 1991, 86(9), 1251-1254.

[105] Prince, J.S.; Senac, M.O. Ceftriaxone associated nephrolithiasis and biliary pseudolithiasis in a child. Pediatric Radiol., 2003, 33 (9), 648-651.

[106] Gulian, J.M.; Gonard, V.; Dalmasso, C.; Palix, C. Bilirubin displacement by ceftriaxone in neonates: evaluation by determination of free bilirubin and erythrocyte-bound bilirubin. Antimicrob. Chemother., 1987, 19, 823-829.

[107] Zafrani, E.S.; Ishak, K.G.; Rudzki, C. Cholestatic and hepatocellular injury associated with erythromycin esters: report of nine cases. Am. J. Dig. Dis., 1979, 24, 385-396.

[108] Chandrupatla, S.; Demetris, A.J.; Rabinowitz, M. Azythromycin-induced intrahepatic cholestasis. Dig. Dis. Sci., 2002, 47, 2186-2188.

[109] Allegaert, K.; van den Anker, J. In: Developmental Nephrology; Fanos V.; Chevalier, R.L.; Faa, G.; Cataldi L. Eds.; Hygeia Press: Quartu S. Elena, 2011; pp. 149-157.

[110] Gupta, R.; Kim, J.Y.; Espinal, M.A. et al. Public Health. Responding to market failures in tuberculosis control. Science, 2001, 293, 1049-1051.

[111] Trollfors, B.; Norrby, R.; Bergmark, J.; Linderholm, H. Comparative toxicity of gentamicin and cefotetan. Scand. J. Infect. Dis., 1986, 18, 139-146.

[112] Zager, R.A. Subclinical gentamycin nephrotoxicity: a potential risk factor for exaggerated endotoxin-driven TNF- $\alpha$ production. Am. J. Physiol. Renal. Physiol., 2007, 293, F1373-F1380.

[113] Lv, H.; Liu, L.; Zhang, Y.; Lu, J.; Chen, X. Ingenuity pathway analysis of urine metabonomics phenotypes toxicity of gentamicin in multiple organs. Mol. Biosyst., 2010, 6, 2056-2067.

[114] Crann, S.A.; Huang, M.Y.; McLaren, J.D.; Schacht, J. Formation of a toxic metabolite from gentamicin by a hepatic cytosolic fraction. Biochem. Pharmacol., 1992, 43, 1835-1839.

[115] Landers, S.; Berry, P.L.; Kearns, G.L.; Kaplan, S.L.; Rudolph, A.J. Gentamicin disposition and effect on development of renal function in the very low birth weight infant. Dev. Pharmacol. Ther., 1984, 7(5), 285-302.

[116] Aust, G. Vestibulotoxicity of gentamicin in newborns at risk. Int. Tinnitus. J., 2001, 7, 27-29.

[117] Alkahtani, S.; Alarifi, S.A.; Al-Doaiss, A.A. Detection of apoptosis induced by gentamicin in rat hepatocytes. International Journal of Zoological Research, 2009, 5, 161-170

[118] Weiss, C.F.; Glazko, A.J.; Weston, J.K. Chloramphenicol in the newborn infant: a physiologic explanation of its toxicity when given in excessive doses. N. Engl. J. Med., 1960, 262, 787-794.

[119] Young, W.S.; Lietman, P.S. Chloramphenicol glucuronyl transferase: assay, ontogeny and inducubulity. J. Pharmacol. Exp. Ther, 1978, 204, 203-211.

[120] Khandelwal, N.; James, L.P.; Sanders, C.; Larson, A.M.; Lee, W.M.; and the Acute Liver Failure Study Group. Unrecognized acetaminophen toxicity of indeterminate acute liver failure. Hepatology, 2011, 53, 567-76

[121] Murray, K.F.; Hadzic, N.; Wirth, S.; Bassett, M.; Kelly, D. Drug-related hepatotoxicity and acute liver failure. J. Pediatr. Gastroenterol. Nutr., 2008, 47, 395-405.

[122] Marzullo, R. An update on N-acetylcysteine tratment for acute acetaminophen toxicity in children. Curr. Opin. Pediatr., 2005, 17, 239-245.

[123] Larson, J.S.; Poison, J.; Fontana, R.J.; Davern, T.J.; Lalani, E.; Hynan, L.S.; Reisch, J.S.; Schiødt, F.V.; Ostapowicz, G.; Shakil, A.O.; Lee, W.M.; Acute Liver Failure Study Group. Acetaminophen-induced acute liver failure: results of a United States multicenter, prospective study. Hepatology, 2005, 
42, 1364-1372.

[124] Miller, R.P.; Roberts, R.J.; Fischer, L.J. Acetaminophen elimination kinetics in neonates, children, and adults. Clin. Pharmacol. Ther, 1976, 19, 284-294.

[125] Roberts, E.A. In: Liver Disease in Children; Suchy, F.J.; Sokol, R.J.; Balistreri, W.F. Eds.; Lippincot Williams \& Wilkins Co.: Philadelphia, 2001, pp. 463-491.

[126] Dart, R.C.; Bailey, E. Does therapeutic use of acetaminophen cause acute liver failure? Pharmacotherapy, 2007, 27, 1219-1230.

[127] Walls, L.; Baker, C.F.; Sarkar, S. Acetaminophen-induced hepatic failure with encephalopathy in a newborn. J. Perinatol., 2007, 27, 133-135.

[128] Ebenezer, K.; Agarwal, I.; Fleming, D. Acute hepatic failure in an infant caused by acetaminophen (paracetamol) toxicity. Ann. Trop. Paediatr., 2008, 28, 301-303. Squires, R.H. Jr.; Shneider, B.L.; Bucuvalas, J.; Alonso, E.; Sokol, R.J.; Narkewicz, M.R.; Dhawan, A.; Rosenthal, P.; Rodriguez-Baez, N.; Murray, K.F.; Horslen, S.; Martin, M.G.; Lopez, M.J.; Soriano, H.; McGuire, B.M.; Jonas, M.M.; Yazigi, N.; Shepherd, R.W.; Schwarz, K.; Lobritto, S.; Thomas, D.W.; Lavine, J.E.; Karpen, S.; Ng, V.; Kelly, D.; Simonds, N.; Hynan, L.S. Acute liver failure in children: the first 348 patients in the pediatric acute liver failure study group. J. Pediatr., 2006, $148,652-658$.

[129] Hu, J.; Yan, D.; Gao, J.; Xu, C.; Yuan, Y.; Zhu, R.; Xiang, D.; Weng, S.; Han, W.; Zang, G.; Yu, Y. rhIL-1Ra reduces hepatocellular apoptosis in mice with acetaminophen-induced acute liver failure. Lab. Invest., 2010, 90, 1737-1746.

[130] Hu, B.; Colletti, L.M. CXC receptor-2 knockout genotype increases X-linked inhibition of apoptosis protein and protects mice from acetaminophen hepatotoxicity. Hepatology, 2010, 5, 691-702.

[131] Jaeschke, H.; Williams, C.D.; Farhood, A. No evidence for caspasedependent apoptosis in acetaminophen hepatotoxicity. Hepatology, 2011, 53, 718-719.

[132] Ishak, K.G. Granulomas of the liver. Adv. Pathol. Lab. Med., 1995, 8, 247361 .

[133] Holt, M.P.; Cheng, L.; Ju, C. Identification and characterization of infiltrating mecrophages in acetaminophen-induced liver injury. J. Leukoc. Biol., 2008, 84, 1410-1421.

[134] Ishida, Y.; Kondo, T.; Kimura, A.; Tsuneyama, K.; Takayasu, T.; Mukaida, $\mathrm{N}$. Opposite roles of neutrophils and macrophages in the pathogenesis of acetaminophen-induced acute liver injury. Eur. J. Immunol., 2006, 36, 10281038.

[135] Ishida, Y.; Kondo, T.; Ohshima, T.; Fujiwara, H.; Iwakura, Y.; Mukaida, N. A pivotal involvement of IFN-gamma in the pathogenesis of acetaminopheninduced acute liver injury. FASEB J., 2002, 16, 1227-1236.

[136] Claridge, L.C.; Eksteen, B.; Smith, A.; Shah, T.; Holt, A.P. Acute liver failure after administration of paracetamol at the maximum recommended daily dose in adults. BMJ, 2010, 341, c6764.

[137] Claridge, L.C. Detection of acetaminophen-cysteine adducts in cases of indeterminate liver failure is not diagnostic of intentional dose. Hepatology, 2011, 54, 746-747.

[138] Au, J.S.; Navarro, V. J.; Rossi, S. Drug-induced liver injury, its pathophysiology and evolving diagnostic tools. Alimentary pharmacology and therapeutics, 2011; 2034 (1), 11-20.

[139] O'Connell, T.M.; Watkins, P.B. The application of metabonomics to predict drug-induced liver injury. Clinical pharmacology and therapeutics, 2010, 88, 394-399.

[140] Russo, R; Capasso M; Paolucci P; Iolascon, A.; TEDDY European Network of Excellence. Pediatric pharmacogenetic and pharmacogenomic studies: the current state and future perspectives. European journal of clinical pharmacology, 2011, 67 (Suppl 1),17-27.

[141] Chen, C.; Krausz, K.W.; Shah, M.Y. Idle, J.R.; Gonzalez, F.J. Serum Metabolomics Reveals Irreversible Inhibition of Fatty Acid-Oxidation through the Suppression of PPARr Activation as a Contributing Mechanism of Acetaminophen-Induced Hepatotoxicity. Chem. Res. Toxicol., 2009, 22, 699-707.

[142] Clayton, T.A.; Baker, D.; Lindon, J.C.; Everett, J.R.; Nicholson, J.K. Pharmacometabonomic identification of a significant host-microbiome metabolic interaction affecting human drug metabolism. Proc. Natl. Acad. Sci. USA, 2009, 106, 14728-14733.

[143] Ellinger-Ziegelbauer, H.; Adler, M.; Amberg, A.; Brandenburg, A.; Callanan, J.J.; Connor, S.; Sieber, M.; Sposny, A.; Suter, L.; Sweatman, B.; Mally, A. The enhanced value of combining conventional and "omics" analyses in early assessment of drug-induced hepatobiliary injury. Toxicol. Appl. Pharmacol., 2011, 252, 97-111.

[144] Fanos, V.; Barberini, L.; Antonucci, R.; Atzori, L. Metabolomics in Neonatology and Pediatrics. Clin. Biochemistry, 2011, 44(7), 452-454.

[145] Fanos, V.; Barberini, L.; Antonucci, R.; Atzori, L. Pharmacometabolomics in Neonatology: is it a dream or a fact? Current Pharmac Design, 2012 (in press).

[146] Fanos, V.; Mussap, M.; Cuzzolin, L.; Antonucci, R.; Tomé, T.; Guimaraes, $\mathrm{H}$. Renal safety of antifungals and non-steroidal anti-inflammatory drugs in the newborn. In: Developmental Nephrology: from embryology to metabolomics, Fanos, V.; Chevalier, R.L.; Faa, G.; Cataldi, L. Eds.; Hygeia Press: Quartu Sant'Elena (Cagliari), Italy, 2011, pp. 131-148.

[147] Aranda, J.V.; Beharry, K.D.; Valencia, G.B. Nonsteroidal anti-inflammatory drugs (NSAIDs) in the newborn - which ones? J. Maternal-Fetal Neonatal. Med., 2009, 22, 21-22.
[148] Aranda, J.V.; Thomas, R. Systematic review: intravenous Ibuprofen in preterm newborns. Semin Perinatol, 2006, 30, 114-120.

[149] Van Overmeire, B.; Smets, K.; Lecoutere, D.; Van de Broek, H., Weyler. J.; Degroote, K.; Langhendries, J.P. A comparison of ibuprofen and indomethacin for closure of patent ductus arteriosus. New Engand J. Med., 2000, 343, 674-678.

[150] Heymann, M.A.; Rudolph, A.M.; Silverman, N.H. Closure of the ductus arteriosus in premature infants by inhibition of prostaglandin synthesis. New England J. Med., 1976, 295, 530-533.

[151] Antonucci, R.; Cuzzolin, R.; Arceri, A.; Dessì, A.; Fanos, V. Changes in urinary PGE2 after ibuprofen treatment in preterm infants with patent ductus arteriosus. Eur. J. Clin. Pharmacol., 2009, 65, 223-230.

[152] Itabashi, K.; Ohno, T.; Nishida, H. Indomethacin responsiveness of patent ductus arteriosus and renal abnormalities in preterm infants treated with indomethacin. J. Pediatr., 2003, 143, 203-207.

[153] Lago, P.; Bettiol, T.; Salvatori, S.; Pitassi, I.; Vinello, A.; Chiandetti, L.; Saia, O.S. Safety and efficacy of ibuprofen versus indomethacin in preterm infants treated for patent ductus arteriosus: a randomized controlled trial. Eur. J. Pediatr., 2002, 161, 202-207.

[154] Patel, J.; Roberts, I.; Azzopardi, D.; Hamilton, P.; Edwards, A. Randomized double-blind controlled trial comparing the effects of ibuprofen with indometacin on cerebral hemodynamics in preterm infants with patent ductus arteriosus. Pediatr. Res., 2000, 47, 36-42.

[155] Pezzati, M.; Vangi, V.; Biagiotti, R.; Bertini, G.; Ciaciulli, D.; Rubaltelli, F. Effects of indomethacin and ibuprofen on mesenteric and renal blood flow in preterm infants with patent ductus arteriosus. J. Pediatr., 1999, 135, 733738.

[156] Grosfeld, J.; Chaet, M.; Molinari, F.; Engle, W.; Engum, S.A.; West, K.W Rescorla, F.J., Scherer, L.R. Increased risk of necrotizing enterocolitis in premature infants with patent ductus arteriosus treated with indomethacin. Ann. Surg., 1996, 224, 350-357.

[157] Guthrie, S.; Gordon, P.; Thomas, V.; Thorp, J.; Peabody, J.; Clark, R. Necrotizing enterocolitis among neonates in the Unites States. J. Perinatol., 2003, 23, 278-285.

[158] Fenech, F.F.; Bannister, W.H.; Grech, J.L. Hepatitis with biliverdinemia in association with Indomethacin therapy. Br. Med. J., 1967, 15, 155-156.

[159] Kelsey, W.M.; Scharyj, M. Fatal hepatitis probably due to indomethacin. JAMA, 1967, 199, 586-587.

[160] Balduck, N.; Otten, J.; Verbruggen, L.; Bougatef, A.; Ramet, J.; Piepsz, A Sudden death of a child with juvenile chronic arthritis, probably due to indomethacin. Eur. J. Pediatr., 1987, 146, 620.

[161] Thomas, R.; Parker, G.; Van Overmeire, B.; Aranda, J. A meta-analysis of ibuprofen versus indomethacin for closure of patent ductus arteriosus. Eur. $J$. Pediatr., 2005, 164, 135-140.

[162] Ohlsson, A.; Walia, R.; Shah, S. Ibuprofen for the treatment of patent ductus arteriosus in preterm and/or low birth weight infants. Cochrane Database Syst Rev, 2008, 1, CD003481.

[163] Mercanti, I.; Boubred, F.; Simeoni, U. Therapeutic closure of the ductus arteriosus: benefits and limitations. J. Maternal-Fetal Neonatal. Med., 2009, 22(S3), 14-20.

[164] Gournay, V.; Savagner, C.; Thiriez, G.; Kuster, A.; Roze, J. Pulmonary hypertension after ibuprofen prophylaxis in very preterm infants. Lancet, 2002, 359, 1486-1488.

[165] Laurent, S.; Rahier, J.; Geubel, A.P.; Lerut, J.; Horsmans, Y. Subfulminant hepatitis requiring liver transplatation following ibuprofen overdose. Liver, 2000, 20, 93-94.

[166] Alam, I.; Ferrell, L.D.; Bass, N.M. Vanishing bile duct syndrome temporally associated with ibuprofen use. Am. J. Gastroenterol., 1996, 91, 1626-1630.

[167] Srivastava, M.; Perez-Ataide, A.; Jonas, M.M. Drug-associated acute onset vanishing bile duct and Stevens-Johnson syndrome in a child. Gastroenterology, 1998, 115, 743-746.

[168] Guimaraes, H.; Rocha, G.; Tomé, T.; Anatolitou, F.; Sarafidis, K.; Fanos, V. Non-steroid anti-inflammatory drugs in the treatment of patent ductus arteriosus in European newborns. J. Maternal-Fetal Neonatal. Med., 2009, 22, 77-80.

[169] Zucker, P.; Daum, F.; Cohen, M.I. Aspirin hepatitis. Am. J. Dis. Child., 1975, 129, 1433-1434.

[170] Prescott, L.F. Hepatotoxicity of mild analgesics. Br. J. Clin. Pharmacol., 1980, 10 (Suppl), 373S-379S.

[171] Tanret, I.; Duh, D. The Reye Syndrome. J. Pharm. Bel., 2011, 1, 13-15.

[172] Pugliese, A.; Beltramo, T.; Torre, D. Reye's and Reye's-like syndromes. Cell Biochem. Funct., 2008, 26, 741-746.

[173] White, J.M. Reye's syndrome and salicylates (letter). JAMA, 1987, 258, 3117.

[174] Cag, M.; Saouli, A.C.; Audet, M.; Wolf, P.; Cinqualbre, J. Reye syndrome and liver transplantation. Turk. J. Pediatr., 2010, 52, 662-664.

[175] Macdonald, S. Aspirin use to be banned in under 16 year olds. British Med. J., 2002, 375, 988 .

[176] Belay, E.D.; Bresee, J.S.; Holman, R.C.; Khan, A.S.; Shahriari, A. Schonberger, L.B. Reye's syndrome in the United States from 1981 through 1997. New England J. Med., 1999, 340, 1377-1382.

[177] Eadie, M.J.; Hooper, W.D.; Dickinson, R.G. Valproate-associated hepatotoxicity and its biochemical mechanisms. Med. Toxicol. Adverse Drug Exp., 1988, 3, 85-105.

[178] Dickinson, R.G.; Hooper, W.D.; Dunstan, P.R.; Eadie, M.G. Urinary 
excretion of valproate and some metabolites in chronically treated patients. Ther. Drug Monit., 1989, 11, 127-133.

[179] Dreifuss, F.E.; Santilli, N.; Langer, D.H.; Sweeney, K.P.; Moline, K.A.; Menander, K.B. Valproic acid hepatic fatalities: a retrospective review. Neurology, 1987, 37, 379-385.

[180] Bryant, A.E.; Dreifuss, F.E. Valproic acid hepatic fatalities, III: U S experience since 1986. Neurology, 1996, 46, 465-469.

[181] Scheffner, D.; Konig, S.; Rauterberg-Ruland, I.; Kochen, W.; Hofmann, W.J.; Unkelbach, S. Fatal liver failure in 16 children with valproate therapy. Epilepsia, 1988, 29, 530-542.

[182] Krahenbuhl, S.; Brandner, S.; Kleinle, S.; Liechti, S.; Straumann, D. Mitochondrial diseases repesent a risk factor for valproate-induced fulminant liver failure. Liver, 2000, 20, 346-348.

[183] Appleton, R.E.; Farrell, K.; Applegarth, D.A.; Dimmick, J.E.; Wong, L.T.; Davidson, A.G. The high incidence of valproate hepatotoxicity in infants may relate to familial metabolic defects. Can. J. Neurol. Sci., 1990, 17, 145148.

[184] Fromenty, B.; Pessayre, D. Inhibition of mitochondrial beta-oxidation as a mechanism of hepatotoxicity. Pharmacol. Ther, 1995, 67, 101-54.

[185] Kesterson, J.W.; Granneman, G.R.; Machinist, J.M. The hepatotoxicity of valproic acid and its metabolites in rats. I. Toxicologic, biochemical and histopathologic studies. Hepatology, 1984, 4, 1143-1152.

[186] Shen, D.D.; Pollack, G.M.; Cohen, M.E. Effect of age on the serum metablite pattern of valproic acid in epileptic children. Epilepsia , 1984, 5, 674

[187] Levy, R.H.; Rettenmeier, A.W.; Anderson, G.D.; Wilensky, A.J.; Friel, P.N.; Baillie, T.A.; Acheampong, A.; Tor, J.; Guyot, M.; Loiseau, P. Effects of polytherapy with phenytoin, carbamazepine, and stiripentol on formation of 4-ene-valproate: a hepatotoxic metabolite of valproic acid. Clin. Pharmacol. Ther., 1990, 48, 225-235

[188] Schlienger, R.G.; Knowles, S.R.; Shear, N.H. Lamotrigine-associated anticonvulsant hypersensitivity syndrome. Neurology, 1998, 51, 1172-1175.

[189] Anderson, G.D.; Yau, M.K.; Gidal, B.E.; Harris, S.J.; Levy, R.H.; Lai, A.A.; Wolf, K.B.; Wargin, W.A.; Dren, A.T. Bidirectional interaction of valproate and lamotrigine in healthy subjects. Clin. Pharmacol. Ther., 1996, 60, 145156.

[190] Maggs, J.L.; Nasibitt, D.J.; Tattey, J.N.A.; Pirmohamed, M.; Park, B.K. Metabolism of lamotrigine to a reactive arene oxide intermediate. Chem. Res.
Toxicol, 2000, 13, 1075-1081.

[191] Mockli, G.; Crowley, M.; Stern, R.; Warnock, M.L. Massive hepatic necrosis after administration of phenobarbital. Am. J. Gastroenterol., 1989, 84, 820822.

[192] Cohen, K.A.; Hopkins, J.; Ingraham, R.H. Characterization of the binding site for nevirapine (BI-RG-587), a nonnucleoside inhibitor of human immunodeficiency virus type-1 reverse transcriptase. J. Biol. Chem., 1991, 266, 14670-14674

[193] Johnson, S.; Chan, J.; Bennett, C.L. Hepatotoxicity after prophylaxis with a nevirapine-containing antiretroviral regimen. Ann. Intern. Med., 2002, 137 , 146-147.

[194] Stern, J.O.; Robinson, P.A.; Love, J. A. Comprehensive hepatic safety analysis of nevirapine in different populations of HIV infected patients. $J$ Acquir. Immune Defic. Syndr., 2003, 34, S21-S33.

[195] McKoy, J.M.; Bennett, C.L.; Scheetz, M.H.; Differding, V.; Chandler, K.L.; Scarsi, K.K.; Yarnold, P.R.; Sutton, S.; Palella, F.; Johnson, S.; Obadina, E.; Raisch, D.W.; Parada, J.P. Hepatotoxicity associated with long-versus shortcourse HIV-prophylactic nevirapine use: a systematic review and metaanalysis from the research on adverse drug events and reports (RADAR) project. Drug Saf., 2009, 32, 147-158.

[196] Andreu, V.; Mas, A.; Bruguera, M.; Salmerón, J.M.; Moreno,V.; Nogué, S. Rodés, J. Ectasy: a common cause of severe acute hepatotoxicity. $J$ Hepatol., 1998, 29, 394-397.

[197] Dykhuizen, R.S.; Brunt, P.W.; Atkinson, P.; Simpson, J.G.; Smith, C.C Ectasy induced hepatitis mimiking viral hepatitis. Gut, 1995, 36, 939-941.

[198] Nunez, O.; Banares, R.; Barrio, J.; Menchén, L.; Diego, A.; Salinero, E.; Clemente, G. Variability of the clinical expression of ectasy-induced hepatotoxicity. Gastroenterol. Hepatol., 2002, 25, 497-500.

[199] Lange-Brock, N.; Berg, T.; Muller, A.R.; Fliege, H.; Neuhaus, P.; Wiedenmann, B.; Klapp, B.F.; Mönnikes, H. Acute liver failure following the use of ectasy (MDMA). Z. Gastroenterol., 2002, 40, 581-586.

[200] Dahshan A. Prenatal exposure to methanphetamine presenting as neonatal cholestasis. J. Clin. Gastroenterol., 2009, 43, 88-90.

[201] Fanos, V.; Cuzzolin, L.; Atzei, A.; Testa, M. Antibiotics and antifungals in neonatal intensive care units: a review. $J$. Chemother, 2007, 19, 5-20.

[202] Heiman, G. Enteral absorption and bioavailability in children in relation to age. Eur J Clin Pharmacol, 1980, 18, 43-50. 